\title{
The Contingent Electoral Impacts of Programmatic Policies: Evidence From Education Reforms in Tanzania*
}

\author{
James Habyarimana ${ }^{1}$, Ken Ochieng' Opalo ${ }^{2}$ and Youdi Schipper ${ }^{3}$ \\ ${ }^{1}$ Georgetown University \\ ${ }^{2}$ Georgetown University \\ ${ }^{3}$ VU University Amsterdam, AIGHD
}

January 18, 2021

\begin{abstract}
A large literature documents the electoral benefits of clientelist and programmatic policies in low-income states. We extend this literature by showing the cyclical electoral responses to a large programmatic intervention to expand access to secondary education in Tanzania over multiple electoral periods. Using a difference-in-difference approach, we find that the incumbent party's vote share increased by 2 percentage points in the election following the policy's announcement as a campaign promise (2005), but decreased by -1.4 percentage points in the election following implementation (2010). We find no discernible electoral impact of the policy in 2015, two electoral cycles later. We attribute the electoral penalty in 2010 to how the secondary school expansion policy was implemented. Our findings shed light on the temporally-contingent electoral impacts of programmatic policies, and highlight the need for more research on how policy implementation structures public opinion and vote choice in low-income states.
\end{abstract}

Keywords: Programmatic Policies, Electoral Accountability, Education, Tanzania

\footnotetext{
${ }^{*}$ We thank seminar participants at Georgetown University (Mortara Seminar Series), the RISE Conference, the London School of Economics Comparative Politics Seminar, CIES Conference, and the World Bank for comments and suggestions during the development of this paper. We also thank David Laitin for commenting on an earlier draft. Ali Hamza, Jessica Hickle, and Katherine Russell provided excellent research assistance. Any errors herein are our own.
} 


\section{Introduction}

Scholars of the politics of public policy in the United States have long observed that "new policies create new politics" and that public opinion regarding programmatic policies can be cyclical conditional on voters' experience. ${ }^{1}$ A related literature in comparative politics examines the electoral impacts of both programmatic and clientelistic policies. These works largely examine whether the provision of public goods and services generate electoral rewards, the politics of clientelism, targeting, and identity/partisan favoritism, and how electoral cycles condition the timing of investments in public goods and services. ${ }^{2}$

This paper extends these two strands of literature by demonstrating the cyclical electoral impacts of a programmatic policy implemented in a low-income state, over multiple electoral periods. Low-income states are ideal sites for studying the cyclical dynamics of policy feedback. Fiscal constraints, lack of bureaucratic capacity, and poor governance often interact with standard distributive politics to complicate voters evaluation of programmatic policies. Furthermore, due to "announcement politics" (pronouncing policies without prior planning), politicians tend to over-promise beyond their states' bureaucratic and fiscal capacities. ${ }^{3}$ The gap between politicians' promises and policy implementation generates important information that shapes public opinion and vote choice in response to programmatic interventions.

We leverage a unique programmatic policy intervention to expand access to secondary education in Tanzania. ${ }^{4}$ Ahead of the 2005 election, the ruling party, Chama Cha Mapinduzi

\footnotetext{
${ }^{1}$ Schattschneider (1935), p. 288. See Soss (1999); Campbell (2003); Mettler (2005); Jacobs and Mettler (2018) for reviews.

${ }^{2}$ See Stasavage (2005); Mani and Mukand (2007); De la O (2012); Stasavage and Harding (2014); Harding (2015); Dionne and Horowitz (2016); Imai, King and Rivera (2020) on electoral rewards associated with public goods; Wantchekon (2003); Magaloni (2006); Hicken (2011); Albertus (2012); Baldwin (2013); Linberg and Weghorst (2013); Kramon and Posner (2016) on clientelism and targeting; and Saez and Sinha (2010); D'Arcy (2013); Baskaran, Min and Uppal (2015) on political business cycles and politicians' effort. Golden and Min (2013) provides a comprehensive review of the distributive politics literature.

${ }^{3}$ See, for example, Dasgupta and Kapur (forthcoming) on "bureaucratic overload" in India and Williams (2017) on uncompleted projects in Ghana. These realities of policy implementation partially explain endemic voter discontent and high electoral turnovers in low-income states (Molina, 2001; Opalo, 2019).

${ }^{4}$ As shown below, the secondary school construction effort was programmatic on account of its scale, geographic spread, and public criteria). Stokes, Dunning, Nazareno and Brusco (2013) define programmatic policies as indiscriminate public programs governed by public criteria.
} 
(CCM), promised to build at least one secondary school in each ward in the country. This was not cheap talk. Between 2005 and 2015 the number of secondary schools quadrupled and enrollment more than tripled, far outstripping the government's optimistic estimates.

How did voters respond to this policy "success" over time? Using a difference-in-difference approach, we find that CCM gained an electoral advantage attributable to the policy in the 2005 election (2 percentage points), followed by a penalty in 2010 (-1.4 percentage points), and no discernible electoral impact in 2015. We also find heterogeneous effects in the 2010 election conditional on prior access to a secondary school. The electoral penalty associated with a new school is just over 4 percentage points in wards with a pre-existing school, compared to a small and statistically insignificant penalty in wards without a pre-existing school. This heterogeneity suggests that prior access to a secondary school anchors voters' expectations of school quality. Our results are robust to controlling for other programs, sample restrictions, as well as a machine-driven matching estimation strategy.

Our empirical strategy is as follows. We evaluate the ward-level electoral impacts of expanding access to secondary education in Tanzania over three electoral cycles. ${ }^{5}$ To that end, we use data from four administrative sources: (i) registration records for the universe of secondary schools (ii) ward-level electoral data from 2000, 2005, 2010, and 2015; (iii) the National Examination Council examination results 2004-2016; and (iv) cartographic data of administrative units in Tanzania between 2002 and 2017. We complement these data with corroborating evidence from Afrobarometer surveys, the Tanzania National Panel Survey, and analyses of the government's education policy documents. Wards comprise our units of analysis. Our dependent variable is the ward-level CCM vote share (based on ward boundaries from 2000), and the independent variable is exposure to school construction within a ward between 2006 and 2010 .

\footnotetext{
${ }^{5}$ Wards are an electoral within Tanzaia's districts. Despite the reintroduction of multiparty elections in 1995, CCM dominates elective positions in Tanzania from the presidency, to parliament, to local government councils. The party has averaged 67 percent of the presidential vote share between 1995-2015. To address potential threats to inference due to endogenous ward splitting across multiple electoral cycles, we use ward boundaries in the year 2000. This means that new wards created after 2000 are collapsed to their respective "parent" wards in 2000.
} 
The findings are consistent with a model in which voters' response to programmatic policies relies on information about costs and benefits revealed at different phases of the policy cycle. ${ }^{6}$ The promise to build at least one secondary school in each ward came before the 2005 election. But the specifics of how this policy would be financed (largely through community contributions) became apparent after the election. While it was common for communities to contribute towards school construction, the sheer scale of secondary school construction after 2006 was unprecedented. Importantly, the construction was financed by an effective tax increase on Tanzanian households. The implicit tax, which was enforced by local government officials, was salient and relatively large. Excluding labor and in-kind contributions, we estimate that the average household's cash contribution in 2007-08 was TSh 36,000 , or about half of the average monthly cash income. ${ }^{7}$

In addition to the financial costs, the policy implementation process also revealed the government's inability to deploy trained teachers and to maintain standards of learning at the new schools. As a result, pass rates in the Certificate of Secondary Education Examination (CSEE) plummeted. In response, in 2013 the government initiated the Big Results Now! (BRN) reform initiative targeted at improving learning outcomes. Pass rates improved after 2013. In Section 6.2, we find no electoral impact of the improvement in learning outcomes in $2015 .{ }^{8}$ Our goal is not to identify the separate electoral impacts of the pieces of information revealed during implementation of the ward secondary school (WSS) policy. We contend that this bundle of signals shaped public opinion in varied ways throughout the policy cycle and over multiple electoral periods.

Overall, our findings have important implications for the study of programmatic policies in low-income electoral democracies. Like in high-income democracies, the process of policy

\footnotetext{
${ }^{6}$ Patashnik and Zelizer (2013); Jacobs and Mettler (2018)

${ }^{7}$ Estimates derived from community module of Tanzania National Panel Survey, 2008-2009. As Languille (2014) documents, "the financial burden of the [secondary school] expansion appeared to fall disproportionately upon communities" (p. 205). Local officials enforced the government's indirect taxation. Households that failed to contribute (cash, construction materials, or labor) were sanctioned - including the confiscation of movable assets like chickens, cattle, and furniture (Kambuga, 2013).

${ }^{8}$ This is consistent with Stasavage and Harding (2014) who find that voters are more likely to reward attributable inputs (e.g. abolition of fees) than learning outcomes.
} 
implementation reveals important pieces of information that shape public opinion and vote choice. In particular, public opinion may change at different stages of the policy cycle - on account of a ratchet up effect on citizens' expectations, revelation of governance lapses (e.g. corruption), or poor implementation due to fiscal constraints or low bureaucratic capacity. ${ }^{9}$ These temporal aspects of public opinion (and vote choice) throughout the policy cycle are unlikely to be captured by static analyses of the electoral impacts of programmatic policies that focus on single elections. ${ }^{10}$

\section{Politics and Policy in Low-Income States}

Low-income states are ideal contexts for studying the dynamics of policy feedback associated with programmatic policies. This is, in part, because weaknesses in policy design, low bureaucratic capacity, and fiscal constraints often introduce significant levels of uncertainly in the policy implementation process. Thus, the process of policy implementation uncovers important new information for voters. Yet much of the research on the politics of policy feedback continues to almost exclusively rely on material evidence from high-income established democracies. ${ }^{11}$ Analyses of policy feedback in low-income states promise to increase our understanding of distributive politics in these contexts. Given the gaps between formal policy goals and actual implementation, there is a lot to be learned about citizens' experiences with policy and how this shapes their perceptions of incumbents' performance over time.

\subsection{New Policies Create New Politics}

A sizable literature documents the electoral rewards of proving public goods and services, ${ }^{12}$ and how incentives for credit-claiming lead politicians to prefer policies whose effects are

\footnotetext{
${ }^{9}$ See Williams 2017; de Kadt and Lieberman 2017; Kruks-Wisner 2018; Dasgupta and Kapur forthcoming

${ }^{10}$ As we show in Appendix C, the dynamics we document are not limited to Tanzania, and may be applicable in other low-income democracies as well.

${ }^{11}$ Beland (2010)

${ }^{12}$ De la O (2012); Stokes et al. (2013); Golden and Min (2013)
} 
easily observable and attributable. ${ }^{13}$ Related works demonstrate how electoral incentives condition the timing, design, and targeting of policies, ${ }^{14}$ as well as the impact of electoral business cycles on incumbent politicians' willingness to exert effort. ${ }^{15}$ A generalized conclusion from this literature is that electoral incentives condition the behavior of politicians, and that the targeted provision of attributable public goods and services wins votes.

Our point of departure is that policy feedback is temporally-dynamic, and that the same programmatic policy may elicit contradictory electoral responses over time. This is for two reasons. First, policies allocate both benefits and costs. ${ }^{16}$ Therefore, studies of programmatic policies should include analyses of electoral responses to both policy costs and benefits. Second, the specific effects of policies on public opinion are temporal and contingent. ${ }^{17}$ For example, a policy that is unpopular at introduction may gain wider public support following implementation and greater public understanding of its benefits (or advocacy by elites). The obverse is also possible. The process of policy implementation may reveal information about government incompetence or hidden costs, leading to a decline in public support for initially popular policies. It follows that a full understanding of the electoral effects of programmatic policies in low-income states requires an explicit consideration of these important features of the policy feedback process.

Beyond their individual-level considerations, programmatic policies may also remake the contours of political mobilization. The costs or benefits associated with a new policy can activate previously latent but powerful political constituencies. ${ }^{18}$ Similarly, policy implementation may reveal new information about politicians' effort, the states' administrative capacities, and quality of service delivery. ${ }^{19}$ Examples abound of policies that upon implementation had in-built self-undermining features and/or elicited political backlash. ${ }^{20}$ New

\footnotetext{
${ }^{13}$ Wantchekon (2003); Stasavage (2005); Mani and Mukand (2007); Stasavage and Harding (2014)

${ }^{14}$ Albertus (2012); Diaz-Cayeros, Magaloni and Estevez (2016)

${ }^{15}$ D'Arcy (2013); Baskaran, Min and Uppal (2015)

${ }^{16}$ Schneider and Ingram (1993); Jacobs and Mettler (2018)

${ }^{17}$ Pierson (1993); Patashnik and Zelizer (2013)

${ }^{18}$ Skocpol (1992)

${ }^{19}$ Pierson (1993); Blimpo, Mensah, Opalo and Shi (2018)

${ }^{20}$ Patashnik (2014); Jacobs and Weaver (2014)
} 
policies may also result in ratcheting preferences for more and higher quality public goods and services, ${ }^{21}$ the consolidation of civic competence and political participation, ${ }^{22}$ or the improvement in state administrative capacities that would in turn expand the scope of citizen demands. ${ }^{23}$ Like in high-income states, programmatic policies can have a contingent and temporally dynamic effect on public opinion and vote choice in low-income states.

\subsection{Electoral Impacts of Policy in Low-Income States}

A couple of factors have contributed to the dearth of research on dynamic responses to the costs of programmatic policies in low-income electoral democracies. First, targeted clientelism (as opposed to programmatic policies) has historically dominated the relationship between voters and politicians in these states. ${ }^{24}$ Second, in most low-income states, heavy reliance on natural resources, trade and consumption taxes, and foreign aid attenuates the political salience of direct taxation as a feature of the policy implementation process. ${ }^{25}$ For instance, Kasara and Suryanarayan attribute the low turnout rates among high-income voters in lowincome states to low fiscal capacity in these contexts. ${ }^{26}$ Stated differently, the historical experience in many low-income states has been that electoral campaign promises rarely come with credible threats of tax increases. As a result, both public discourse and research on policies' benefits seldom address their associated costs.

This is changing. Over the last three decades, many low-income states have implemented large-scale programmatic policies. Regardless of regime type, this shift is attributable to the spread of competitive elections and the emergence of focal global developmental targets such as the Millennium Development Goals. ${ }^{27}$ Recent examples of ambitious programmatic poli-

\footnotetext{
${ }^{21}$ de Kadt and Lieberman (2017); Kruks-Wisner (2018)

${ }^{22}$ Campbell (2003)

${ }^{23}$ Skocpol (1992)

${ }^{24}$ Wantchekon (2003); Hicken (2011)

${ }^{25}$ Morrison (2009); Ahlerup, Baskaran and Bigsten (2015)

${ }^{26}$ Kasara and Suryanarayan (2015)

${ }^{27}$ Easterly (2009)
} 
cies include universal access to primary education, ${ }^{28}$ electricity connectivity, ${ }^{29}$ healthcare,${ }^{30}$ and social protection. ${ }^{31}$ To implement these policies, low-income states increasingly depend on domestic sources of revenue as the importance of foreign aid declines. ${ }^{32}$ These shifts in the scope of public goods and services and the importance of local financing call for studies that address the political economy of both costs and benefits of programmatic policies.

Overall, the expansion of fiscal capacity in low-income states will provide ample opportunities to examine how specific policies shape public opinion, political mobilization, civic attitudes, and vote choice - over time. Government programs will likely endow citizens with both resources and incentives to mobilize - either to support or oppose specific interventions. ${ }^{33}$ Another potential impact of programmatic policies might be the emergence of specialized interest groups and ideological/partisan alliance consolidation. Research on these feedback effects will greatly improve our understanding of the politics of programmatic policies in low-income states. We begin this process by analyzing the temporal electoral impacts of a programmatic effort to expand access to secondary education in Tanzania. ${ }^{34}$

\section{The Policy and Political Context}

Tanzania's experience with education expansion provides important lessons on the cyclical politics of programmatic policies. In 2001 policymakers reintroduced UPE. ${ }^{35}$ Between 2001 and 2010 primary enrollment increased from 4.8 million to 8.4 million. UPE's success considerably increased demand for secondary education. Yet during this period secondary school

\footnotetext{
${ }^{28}$ Stasavage and Harding (2014); Richards and Vining (2015)

${ }^{29}$ Lee, Miguel, Christiano, Meyo, Podolsky, Rosa and Wolfram (2016)

${ }^{30}$ Lagomarsino, Garabrant, Adyas, Muga and Otoo (2012); D’Arcy (2013)

${ }^{31}$ De la O (2012); Diaz-Cayeros, Magaloni and Estevez (2016); Opalo (2020)

${ }^{32}$ See Ahlerup, Baskaran and Bigsten (2015). See also, Anyanzwa, James. 2018. "Higher taxes across East Africa will stifle economic growth, slow investments," The East African, September 8, 2018. Accessed on 2/20/2019: https://bit.ly/2TVtxMc

${ }^{33}$ Pierson (1993); Kruks-Wisner (2018)

${ }^{34}$ As we show in Appendix C, the policy of expanding access to secondary education is not unique to Tanzania. Following successes in expanding access to primary education, several African countries have recently embarked on domestically-funded programs to increase access to secondary education.

${ }^{35}$ URT 2001
} 
enrollment stood at less than 7 percent, with only 21.7 percent of primary school pupils transitioning to secondary school. ${ }^{36}$ It is in this context that in 2005, ahead of a general election, CCM announced its Ward Secondary Schools (hereafter WSS) policy. ${ }^{37}$ At the time of this announcement, only 836 out of Tanzania's 2552 wards had at least one secondary school. Given the widespread demand and clear criteria for implementation (each ward was guaranteed at least one school), the commitment to build at least one secondary school in each ward can be viewed as a programmatic policy. Available data suggest that school construction was widespread, irrespective of ward-level incomes. Importantly, the construction effort was concentrated between 2006 and 2010 (Figure 1). ${ }^{38}$

The WSS policy had the following features. First, secondary school construction was tied to wards, with each guaranteed at least one school. Second, communities provided land and financed initial construction through contributions. Once at least four classrooms were completed, the government provided roofing, registered the new school, posted teachers, and provided operational support. Household contributions could be in cash, labor, or inkind. Ward-level government officials enforced contributions following community meetings to determine each household's contribution. This feature of the policy was not popular. For instance, a ward official reported that "[t]hey can do it [contribute] but only if they are forced. The ones who refused to attend the meetings are taken to the ward executive officer for penalties; their properties taken to be sold and to fund the works." 39 Parents that failed to pay were "forced to contribute through the uambozi practice: the forced requisition of household assets" ${ }^{40}$ Despite the promise of government support after registration, parental contribution remained important for school operations. Based on the Tanzania National Panel Survey, 2008-2009, we estimate the average household contribution to the secondary

\footnotetext{
${ }^{36}$ Mafuru 2011

${ }^{37} \mathrm{CCM}$ is a hegemonic party that has ruled Tanzania since independence and, in addition to the presidency, dominates the legislature and local government councils. The party has a fair amount of internal competition, as well as a well-established countrywide organizational structure that facilitates recruitment and socialization of members (Babeiya, 2011; Morse, 2014; Croke, 2015).

${ }^{38}$ Figure C.5 in Appendix C shows no uptick in primary school construction around the same period.

${ }^{39}$ Languille 2014, p. 122.

${ }^{40}$ Ibid. p. 214
} 
Figure 1: Share of Wards Building New Secondary Schools and Poverty Rates
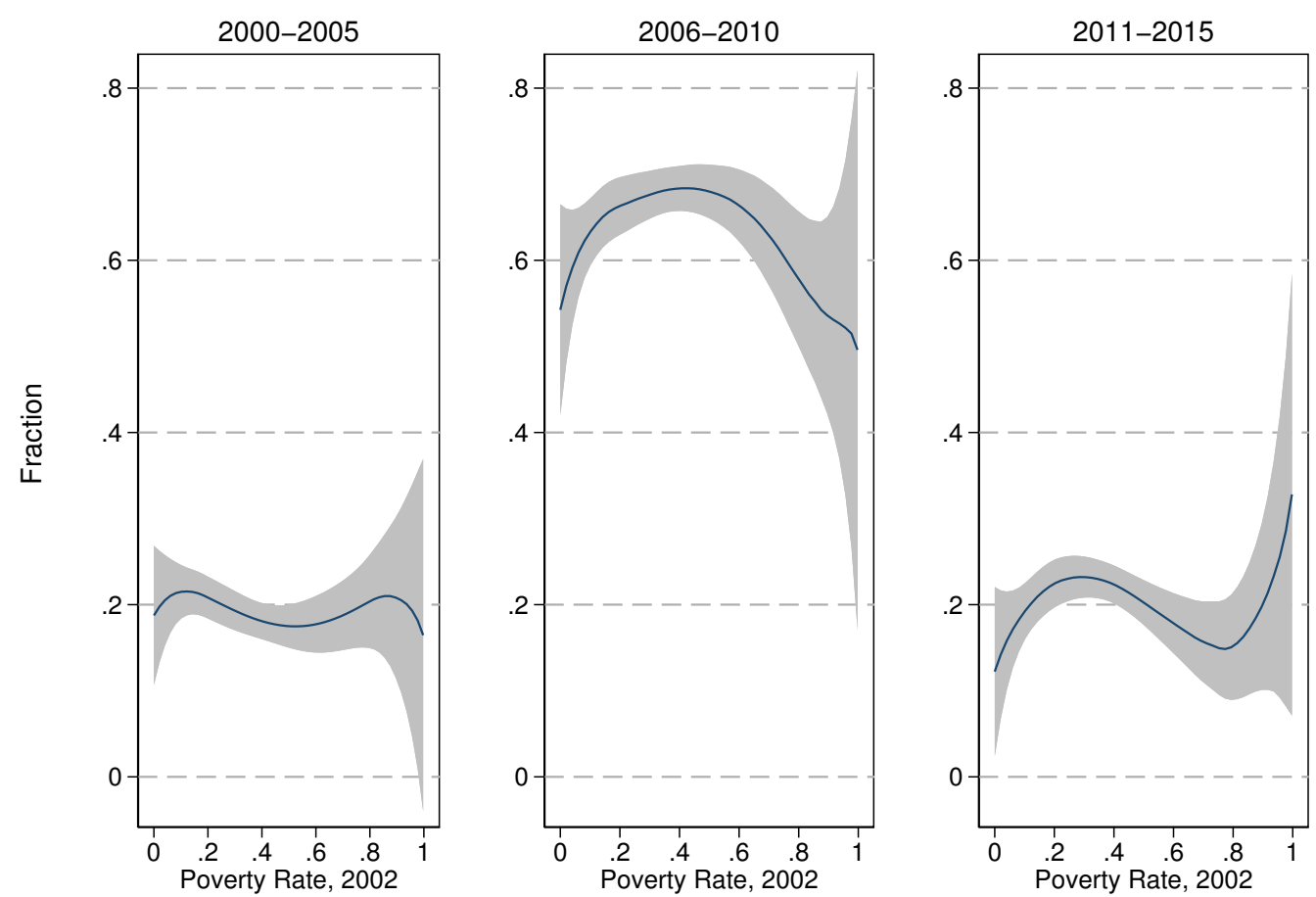

Notes: Panels show non-parametric kernel-weighted local polynomial smoothing relationships between the likelihood of secondary school construction in each period and poverty rate. Shaded areas depict the 95 percent confidence interval. Poverty data are from the 2002 National Census. The data suggest widespread secondary school construction across income brackets, and particularly intense between 2006 and 2010.

school construction effort to have been about 50 percent of monthly cash income. ${ }^{41}$

Third, as shown in Figure 2, the increase in the number of secondary schools (Panel (a)) and student enrollment (Panel (c)) outstripped the government's own plans and capacity to deploy qualified teachers and other forms of promised support. ${ }^{42}$ Overall, per capita budget allocation for secondary education declined. ${ }^{43}$ And despite the increase in the number of teachers from 15,911 in 2007 to 65,513 in 2013, many of these teachers were inadequately trained. ${ }^{44}$ In both new and old schools, precipitous declines in pass rates in the Certificate

\footnotetext{
${ }^{41}$ In a sample of districts, Languille (2014) also estimates that households spent as much as 50 percent of their annual cash income. Once schools were opened, students that were unable to contribute to ongoing construction efforts risked suspension (Mafuru, 2011; Kambuga, 2013).

${ }^{42}$ Data are from World Bank (2004) and URT (2017).

${ }^{43}$ (Languille, 2019)

${ }^{44}$ Sumra and Katabaro 2014
} 
Figure 2: Trends in Secondary Education and Public Opinion

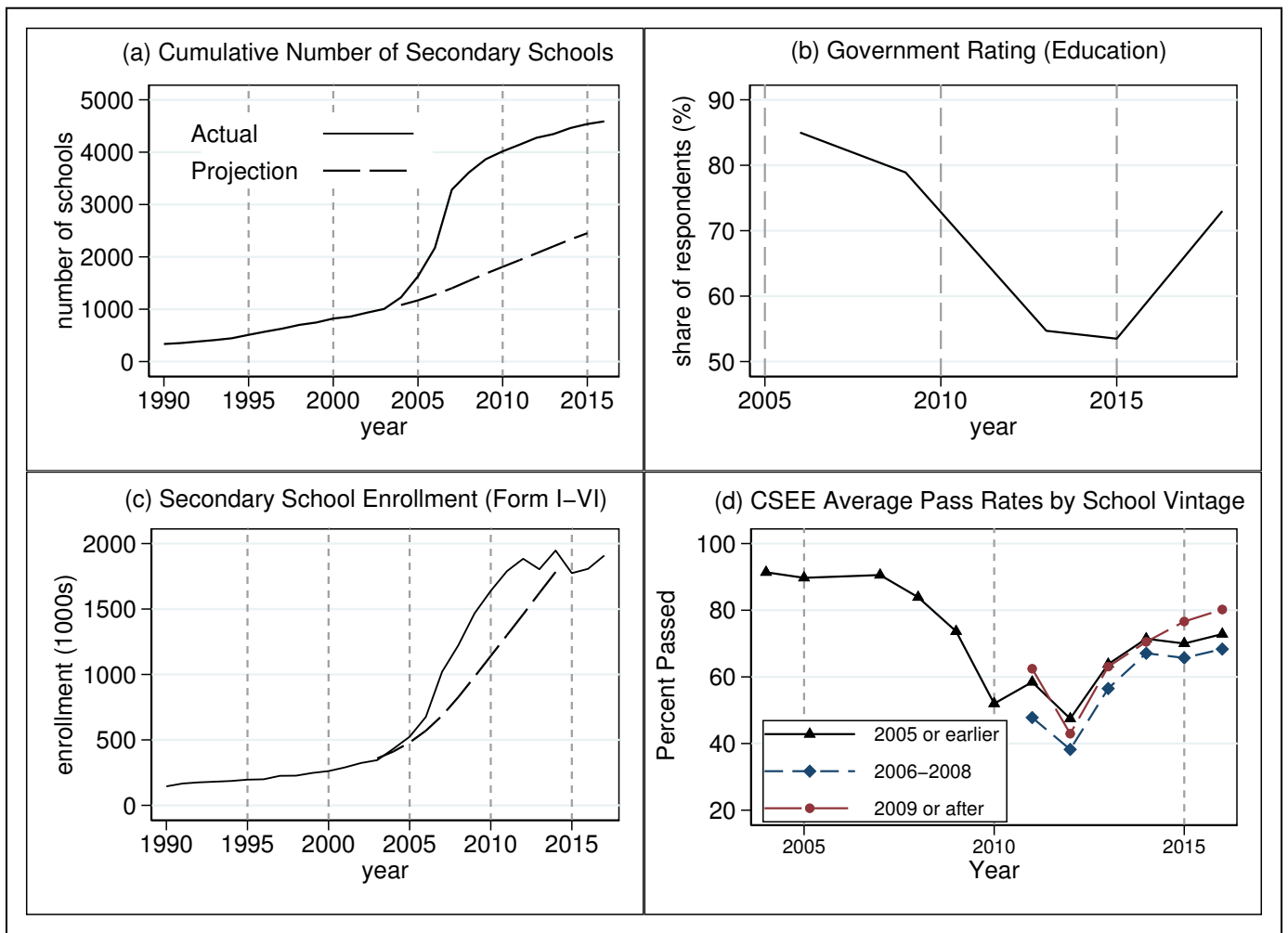

Notes: Figures show the (a) cumulative number of secondary schools, (b) public opinion on government performance in the education sector (from Afrobarometer), (c) trends in secondary school enrollment, and (d) secondary school national examination pass rates by school registration date. In panels (a) and (c), dotted lines represent government projections of the number of schools and student enrollment, respectively. It is clear that both school construction and student enrollment outperformed official projections in the period under study. Trends in panels (b) and (d) show declines in public opinion and learning outcomes in tandem with increases in the number of schools and student enrollment.

of Secondary School Examination (CSEE) followed - from 89.3 percent in 2005 to 43.07 in 2012 (Panel (d)). Survey data from Afrobarometer corroborate these trends (Panel (c)). ${ }^{45}$ The share of respondents stating that describing government performance in the education sector as "fair well" or "very well" declined after 2005, in the midst of a boom in secondary school construction and student enrollment. In 2013, the government responded to public pressure in the wake of the falling pass rates through the Big Results Now! (BRN) initiative - which introduced targeted interventions to improve learning outcomes. ${ }^{46}$ Thereafter pass

\footnotetext{
${ }^{45}$ Afrobarometer Survey, multiple rounds.

${ }^{46}$ Cilliers, Mbiti and Zeitlin 2020.
} 
rates improved, rising to a high of 78.38 percent in $2018 .{ }^{47}$ In Section 6.2 we show that efforts to improve learning outcomes had no discernible electoral impacts in the 2015 election.

Finally, the WSS policy was a textbook example of "announcement politics." Ahead of the 2005 election, the CCM manifesto stated the intention to fully implement the 2004 Secondary Education Development Plan (SEDP). ${ }^{48}$ This promise was politically salient, given the high demand for secondary schools in the wake of UPE's success (See Figure C.4 in Appendix C). ${ }^{49}$ The government's objective in the SEDP was a gradual expansion of access by building classrooms and dozens of new schools each year (see Figure 2). ${ }^{50}$ Yet after the election, in 2006, Prime Minister Edward Lowassa issued a directive to accelerate implementation the policy, to the surprise of bureaucrats. The announcement quickly became policy, forcing bureaucrats to play catch-up and impose significant costs on Tanzanian households.

This brief account highlights important features of policy life-cycles that are common in low-income states. To compound existing fiscal and bureaucratic frailties, policy making and bureaucratic input often lags politicians' "announcement politics". In Tanzania, Lowassa's unanticipated policy announcement gave the bureaucracy and public little time to form accurate expectations of the cost of the WSS program, with most of information only revealed during implementation. As Tanzanians later realized, the WSS policy had both benefits (secondary school access) and costs (an implicit tax increase and deteriorating quality). $A$ priori, the policy's net electoral impact may have been clear in 2005 but unclear in subsequent elections. In 2005, citizens had limited information on the specifics of implementation. But in 2010 and 2015 they had observed a bundle of signals about the policy - including increases in the number of secondary schools, significant taxation, and declining learning outcomes. In light of these features of the WSS policy, our findings should be viewed as

\footnotetext{
${ }^{47}$ See "Ilboru sits 36th in results ranking," The Citizen, January 26, 2019.

${ }^{48}$ Selbervik (2006)

${ }^{49}$ The idea of constructing a secondary school in each ward had been an aspiration of CCM at least since 1995, and appeared in policy documents and the party's manifestos in 2000 and 2005 (Languille, 2014, p. 108). However, the credibility of the promise was amplified by government commitment in the SEDP and the sheer scale of increased demand for secondary schools following UPE's unparalleled success in boosting primary school enrollment.

${ }^{50}$ World Bank (2004)
} 
capturing the temporally-contingent electoral responses to the bundle of signals revealed in the implementation process.

\section{$4 \quad$ Data and Empirical Strategy}

\subsection{The Data}

Answering the research question posed above requires a careful aggregation of numerous administrative datasets. In this section, we describe the data construction process in detail. We rely on data from three main administrative sources. Ward-level electoral data (for 2000, 2005, 2010, and 2015) are from the Tanzania Electoral Commission. School registration data are from the Education Management Information System (EMIS), which conducts annual censuses of schools. ${ }^{51}$ The national censuses from 2002 and 2012 provide ward-level data on household and population characteristics including schooling, occupation, and measures of wealth. ${ }^{52}$ We augment these administrative datasets with cartographic shape files to construct a panel of pre-WSS policy wards. Finally, we overlay this panel with remote sensed night light index data drawn between 1995 and 2015 to examine the plausibility of our identification assumptions.

To maintain our focus on support for CCM, we only use data from the mainland Tanzania (Tanganyika), and exclude all data from Zanzibar. Our unit of analysis is the ward. Ward boundaries, however, are not stable throughout the study period. ${ }^{53}$ We address potentially endogenous boundary changes by fixing the unit of observation to the geographical boundaries of wards in 2000, before the WSS policy. ${ }^{54}$ To link parent wards in 2000 to wards in

\footnotetext{
${ }^{51}$ For our purposes, newly constructed WSS schools are those with registration dates falling between January 12006 and December 312009

${ }^{52}$ We use the small-area estimates based on the 2002 census data to estimate the share of households below the poverty line. See Kilama, Lindeboom and Weide (2006) for the underlying methodology.

${ }^{53}$ The number of wards were 2,523 in 2000, 2552 in 2005, 3,333 in 2010, and 3,944 in 2015.

${ }^{54}$ Unlike other studies that examine outcomes at lower non-splitting levels like villages or sub-counties (Grossman and Lewis, 2014; Billing, 2019), wards are the lowest administrative and electoral units for which the relevant schooling and electoral data is available.
} 
Figure 3: Ward Boundaries Throughout Period Under Study

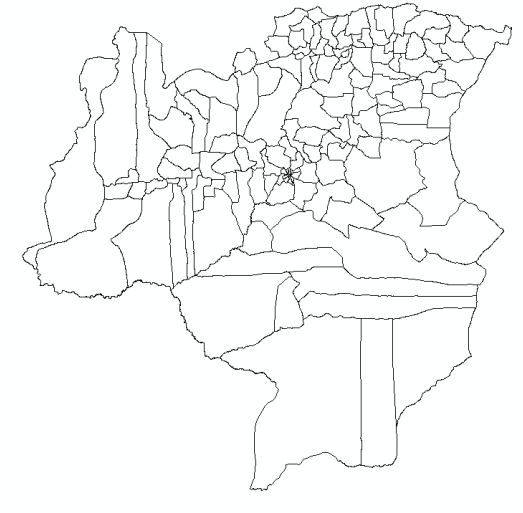

(a) 2002 Wards (census)

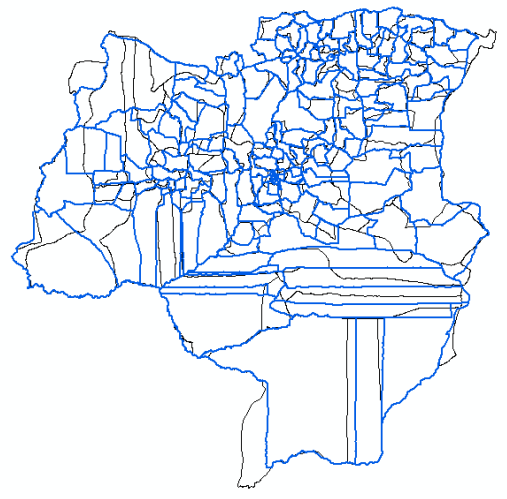

(b) 2012 Wards (census)

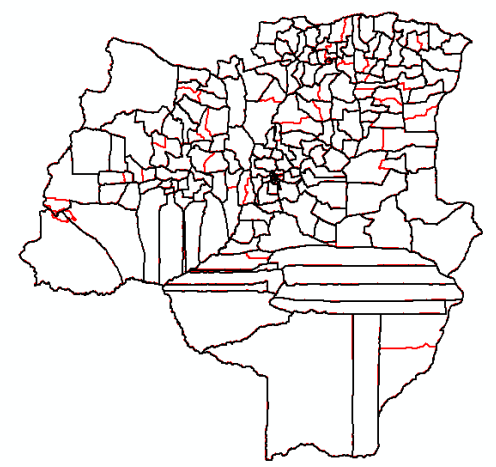

(c) 2015 Wards (2017 data)

Notes: Figures indicate ward boundaries between 2000 and 2015. We use 2002 ward boundaries from the census and electoral data to construct 2000 and 2005 wards (only 29 new wards were created in the five years). We construct the 2010 boundaries from the 2012 census and electoral data. 2015 ward boundaries are from the electoral and 2017 shape files. We collapse new wards in the 2005, 2010, and 2015 elections to their "parent" wards in 2000.

subsequent electoral periods, we define consistent 2000 ward boundaries using geographical information systems (GIS) data from the 2002 population census. We then link this to shape files from the 2012 population censuses as well as updated shape files constructed in July 2017. Figure 3 illustrates the ward matching exercise across multiple electoral periods. Shape files from 2002 allow us to identify "parent" wards in 2000 while the 2012 census shape files enable identification of wards in 2010. Finally, the 2017 shape files identify wards in the 2015 elections. We link wards by overlaying the three shape files above and use overlaps to identify a link between "parent" and "child" wards. We address cartographic inconsistencies, such as when ward boundaries do not perfectly align across waves, by using an overlap threshold of 50 percent to assign a child ward to a parent ward. Overall, we achieve near perfect rates of parent-child matching. ${ }^{55}$

\footnotetext{
${ }^{55}$ See appendix A for further details. This is overlap threshold constraint is especially important in the link between 2002 and 2012 where the overlap between 106 wards in 2002 and 245 wards in 2012 is below the 50 percent threshold. These wards represent about 4.3 percent and 6.2 percent of wards in 2002 and 2012, respectively. Mismatches are considerably lower for the link between 2012 and 2017, where only 11 and 12 wards, respectively are below the overlap threshold.
} 
Having linked pre-WSS wards across elections, we then merge the administrative datasets. We link schools/electoral outcomes and ward characteristics across administrative data sources by following a series of steps to map records into the relevant wards and use the linking of parent and child wards across the four electoral years to create the parent ward panel. Due to inconsistencies in ward and school codes over time, we use flexible stringmatching algorithms to link ward and school names. To address the challenge of similarities in school and ward names across districts, we restrict matching across datasets to membership of the same harmonized district and region . We start by linking the most recent administrative datasets - the education school census data drawn from 2016 and the ward elections data for $2015 .^{56}$ We then merge the linked school census-election dataset to ward election data.

To account for ward fragmentation between 2010 and 2015 (About 20 percent of the 3333 wards in 2010 are split to produce 3944 wards in 2015), we use a two step process to link wards. First, for non-split wards, we use string matching algorithms to link wards across these two election years. This strategy also works for child wards that keep the "parent" ward's name. For unmatched "child" wards, we use the intersection of GIS shape layers for 2012 and 2017 to identify unmatched mother-child ward linkages. We repeat this process to link the resulting 2010-2015 data to the 2000 and 2005 electoral data as well as ward characteristics from the 2002 census. Once again, unmatched wards are linked through intersecting shape files for 2017 and 2002 and using the 50 percent overlap rule to define a link.

Using this process, we successfully link just over 97 percent of wards in 2000 across all electoral cycles, as well as approximately 98 percent of all secondary schools in the 2016 census. Table 1 compares matched and unmatched 2000 parent wards along electoral, school access and socio-economic outcome measures. ${ }^{57}$ On average, 35 percent of households are below the poverty line, 8 percent use electricity for lighting, while under 30 percent use

\footnotetext{
${ }^{56}$ Since, at all points over the four electoral years, there are wards that don't have a school, non-matched wards are not dropped

${ }^{57}$ We define an unmatched parent ward as a ward that cannot be fully linked to at least one ward in each of the three subsequent electoral years
} 
Table 1: Comparison of Matched/Unmatched Wards pre-WSS Policy

\begin{tabular}{lccccc}
\hline Variable & $\begin{array}{c}\text { Matched } \\
(1)\end{array}$ & $\begin{array}{c}\text { Unmatched } \\
(2)\end{array}$ & $\begin{array}{c}\text { Overall } \\
(3)\end{array}$ & $\begin{array}{c}(1) \text { vs }(2), \\
(\mathrm{p} \text {-value })\end{array}$ & $\mathrm{N}$ \\
\hline Total Votes Cast, 2000 & 2592.83 & 3022.40 & 2604.75 & 0.17 & 2523 \\
& $(52.76)$ & $(292.70)$ & $(51.95)$ & & \\
CCM vote share, 2000 & 0.73 & 0.73 & 0.73 & 0.89 & 2520 \\
CHADEMA vote share, 2000 & $(0.00)$ & $(0.02)$ & $(0.00)$ & & \\
& 0.22 & 0.18 & 0.22 & 0.56 & 403 \\
Number of Sec. Schools, 2000 & $(0.01)$ & $(0.06)$ & $(0.01)$ & & \\
& 0.32 & 0.16 & 0.31 & 0.03 & 2523 \\
Share Urban/Peri-Urban & $0.01)$ & $(0.05)$ & $(0.01)$ & & \\
& $(0.01)$ & 0.21 & 0.26 & 0.43 & 2523 \\
Share HH Below Poverty Line & 0.35 & 0.38 & 0.35 & 0.39 & 2374 \\
Share using unprotected wells & $(0.00)$ & $(0.03)$ & $(0.00)$ & & \\
& 0.28 & 0.23 & 0.28 & 0.33 & 2402 \\
Share using electricity lighting & $(0.01)$ & $(0.04)$ & $(0.01)$ & & \\
& 0.08 & 0.05 & 0.08 & 0.34 & 2402 \\
HH owns radio or telephone & $(0.00)$ & $(0.02)$ & $(0.00)$ & & \\
& 0.53 & 0.57 & 0.53 & 0.17 & 2402 \\
Ward-level Illiteracy Rate & $(0.00)$ & $(0.02)$ & $(0.00)$ & & \\
& 0.37 & 0.40 & 0.37 & 0.31 & 2402 \\
Dependency Ratio & $(0.00)$ & $(0.02)$ & $(0.00)$ & & \\
N & 1.74 & 1.66 & 1.73 & 0.26 & 2402 \\
& $(0.01)$ & $(0.04)$ & $(0.01)$ & & \\
\hline
\end{tabular}

Notes: Unit of observation corresponds to a ward defined by boundaries in 2000. Standard errors are in parentheses. Total votes cast, vote shares and number of schools correspond to 2000. All other ward attributes are drawn from aggregated 2002 census data.

protected wells as a source of drinking water. We find no significant differences between matched and unmatched wards. There are also no significant differences in the vote share for both CCM and CHADEMA (the main opposition party). Unmatched wards have more voters, are more rural, and have fewer schools. Notably, the difference in the likelihood of a secondary school is statistically significant at the 5 percent level. Overall, we interpret this table as indicative of limited selection into the study sample.

Table 2 compares selected means of linked/unlinked wards using election-year ward boundaries. We match 96.1 percent of 2005 wards, 97 percent of 2010 wards and 93 percent of 2015 wards. Consistent with the trajectory in presidential elections, there has been 
Table 2: Comparison of Linked/Unlinked Wards in 2005, 2010, and 2015

\begin{tabular}{|c|c|c|c|c|c|}
\hline Variable & $\begin{array}{c}\text { Matched } \\
\text { (1) }\end{array}$ & $\begin{array}{c}\text { Unmatched } \\
(2)\end{array}$ & $\begin{array}{c}\text { Overall } \\
(3)\end{array}$ & $\begin{array}{c}\text { (1) vs. (2), } \\
\text { (p-value) }\end{array}$ & $\mathrm{N}$ \\
\hline \multicolumn{6}{|c|}{ Panel A: 2005} \\
\hline Total Votes in ward & $\begin{array}{c}3947.70 \\
(64.78)\end{array}$ & $\begin{array}{l}4300.55 \\
(371.10)\end{array}$ & $\begin{array}{c}3961.39 \\
(63.91)\end{array}$ & 0.29 & 2552 \\
\hline CCM vote share & $\begin{array}{c}0.72 \\
(0.00)\end{array}$ & $\begin{array}{c}0.70 \\
(0.02)\end{array}$ & $\begin{array}{c}0.72 \\
(0.00)\end{array}$ & 0.18 & 2552 \\
\hline CHADEMA vote share & $\begin{array}{c}0.17 \\
(0.01)\end{array}$ & $\begin{array}{c}0.17 \\
(0.02)\end{array}$ & $\begin{array}{c}0.17 \\
(0.00)\end{array}$ & 0.69 & 1093 \\
\hline Number of Sec. Schools & $\begin{array}{c}0.62 \\
(0.02)\end{array}$ & $\begin{array}{c}0.59 \\
(0.08)\end{array}$ & $\begin{array}{c}0.62 \\
(0.02)\end{array}$ & 0.70 & 2552 \\
\hline$N$ & 2453 & 99 & 2552 & & \\
\hline \multicolumn{6}{|c|}{ Panel B: 2010} \\
\hline Total Votes in ward & $\begin{array}{c}2099.35 \\
(35.16)\end{array}$ & $\begin{array}{l}1627.32 \\
(129.09)\end{array}$ & $\begin{array}{c}2085.05 \\
(34.35)\end{array}$ & 0.02 & 3333 \\
\hline CCM vote share & $\begin{array}{c}0.68 \\
(0.00)\end{array}$ & $\begin{array}{c}0.70 \\
(0.02)\end{array}$ & $\begin{array}{c}0.69 \\
(0.00)\end{array}$ & 0.48 & 3333 \\
\hline CHADEMA vote share & $\begin{array}{c}0.31 \\
(0.00)\end{array}$ & $\begin{array}{c}0.29 \\
(0.02)\end{array}$ & $\begin{array}{c}0.31 \\
(0.00)\end{array}$ & 0.54 & 1856 \\
\hline Number of Sec. Schools & $\begin{array}{c}1.17 \\
(0.02)\end{array}$ & $\begin{array}{c}0.80 \\
(0.07)\end{array}$ & $\begin{array}{c}1.16 \\
(0.02)\end{array}$ & 0.00 & 3333 \\
\hline$N$ & 3232 & 101 & 3333 & & \\
\hline \multicolumn{6}{|c|}{ Panel C: 2015} \\
\hline Total Votes in Ward & $\begin{array}{c}3753.53 \\
(49.91)\end{array}$ & $\begin{array}{c}3108.25 \\
(121.78)\end{array}$ & $\begin{array}{c}3708.37 \\
(47.26)\end{array}$ & 0.00 & 3944 \\
\hline CCM vote share & $\begin{array}{c}0.57 \\
(0.00)\end{array}$ & $\begin{array}{c}0.59 \\
(0.01)\end{array}$ & $\begin{array}{c}0.57 \\
(0.00)\end{array}$ & 0.10 & 3944 \\
\hline CHADEMA vote share & $\begin{array}{c}0.38 \\
(0.00)\end{array}$ & $\begin{array}{c}0.36 \\
(0.01)\end{array}$ & $\begin{array}{c}0.37 \\
(0.00)\end{array}$ & 0.31 & 3334 \\
\hline Number of Sec. Schools & $\begin{array}{c}1.15 \\
(0.02)\end{array}$ & $\begin{array}{c}0.74 \\
(0.06)\end{array}$ & $\begin{array}{c}1.12 \\
(0.02)\end{array}$ & 0.00 & 3944 \\
\hline$N$ & 3668 & 276 & 3944 & & \\
\hline
\end{tabular}

Notes: Geographic unit of observation corresponds to ward boundaries corresponding to each election year shown in panels A, B and C. Standard errors in parentheses. Unmatched wards are wards for each election year that are not linked throughout the four elections.

a steady decline in the support for CCM ward councilor candidates. Average vote share for CCM candidates in ward elections falls from 72 percent in 2005 and 69 percent in 2010 to 57 percent in 2015. There is a also a considerable increase in the number of wards across election cycles starting with just over 2500 wards in 2005 and ending with just under 4000 in 
2015. Unmatched wards have significantly fewer secondary schools, particularly in 2010 and 2015. Importantly, there is no difference in our outcome variable, CCM vote share, between matched and unmatched wards in each of these years. ${ }^{58}$

Of singular importance to this paper is the increase in the number of schools per ward. The share of wards without secondary schools decreased from 83 percent in 2000 to 65 percent in 2005 and 15 percent in 2010. By 2015, only 10 percent of wards lacked a secondary school. As shown in Figures 1 and 2, school construction was widespread and concentrated between 2006 and 2010. The sheer scale of school construction, under a simple and publicized criterion (a school per ward), justifies the characterization of WSS as a programmatic policy.

\subsection{Empirical Strategy}

Our goal is to estimate the electoral effects of the full cycle of secondary school expansion under the 2005 Ward secondary school (WSS) policy, from announcement to implementation and utilization, and over three electoral cycles. Specifically, we estimate the electoral effects, across the 2005, 2010 and 2015 elections, of a ward school being built and opened between 2006 and the beginning of 2010. Our empirical strategy uses a generalized difference-indifferences estimation of the form:

$$
Y_{i j}=\beta_{0}+\sum_{j} \gamma_{j} * \text { Election }_{j}+\sum_{j} \beta_{j} D_{i} * \text { Election }_{j}+\varepsilon_{i j}
$$

where $Y_{i j}$ represents an outcome variable of interest - which in our case is the CCM candidate vote share in ward $i$ in election $j . D_{i}$ is an indicator that takes on the value of 1 if at least one secondary school was registered between 2006 and 2010 in ward $i$ and 0 otherwise. Election $_{j}$ is an indicator that takes on the value of 1 for each election $j=[2000,2005,2010$, 2015] and 0 otherwise. $\beta_{j}$ are the parameters of interest, particularly for $j \neq 2000$. Relative to wards where no schools were built, $\beta_{2005}$ represents the additional CCM vote share due to the

\footnotetext{
${ }^{58} \mathrm{CHADEMA}$ has historically had greater support in urban areas and particularly in earlier elections did not have a grassroots presence in much of rural Tanzania.
} 
announcement of the policy ahead of the 2005 elections in wards where these schools were built. $\beta_{2010}$ represents the relative impact of learning about the costs of a new secondary school in the 2010 elections. Finally, $\beta_{2015}$ captures any persistent net electoral costs or benefits of constructing and operating a school in the 2015 election.

While the difference-in-differences strategy in equation 1 sweeps out time-invariant heterogeneity, our estimates will be biased if, for example, trends in electoral support for CCM differ between program and non-program wards. There are a number of plausible mechanisms that can produce differential trends. For instance it is possible that trends in support for CCM are correlated with demand for schooling or capacity to mobilize resources and/or collective action to construct schools. Alternatively, our inference may be confounded by other government programs located in WSS wards.

A formal test of the parallel trends assumption is not feasible due to lack of data from the solitary post one-party state ward-level election in 1994. Instead, we present one piece of suggestive evidence of the plausibility of parallel trends and three strategies to address potential confounds. First, we compare WSS and non-WSS wards (Table 3). As we note above, the WSS program is different from targeted clientelistic interventions designed to shore up CCM support. Consistent with this fact, there are very few significant differences in observable characteristics between WSS and non-WSS wards. The two sets of wards are similar on geographical characteristics (size, elevation and topography), socio-economic characteristics (poverty and other welfare measures) and development measures (night light percentile ranks in 1995, 2000 and 2005). ${ }^{59}$ Program wards have larger populations (p-value $\left.<0.01\right)$, are slightly less supportive of CCM (p-value $<0.05)$, and are less likely to have uncontested elections in 2000 (p-value $<0.1)$. All of these facts are consistent with WSS wards being more urban/peri-urban. The difference in the dependency ratio is statistically significant but substantively small.

\footnotetext{
${ }^{59}$ The ward average night light index used across each of these years comes from a different satellite with different calibrations and positions that make cross year comparisons meaningless. To overcome this limitation, we convert index values to percentile ranks
} 
[Table 3 About Here]

Figure 4: Pre-announcement trends in night light rank

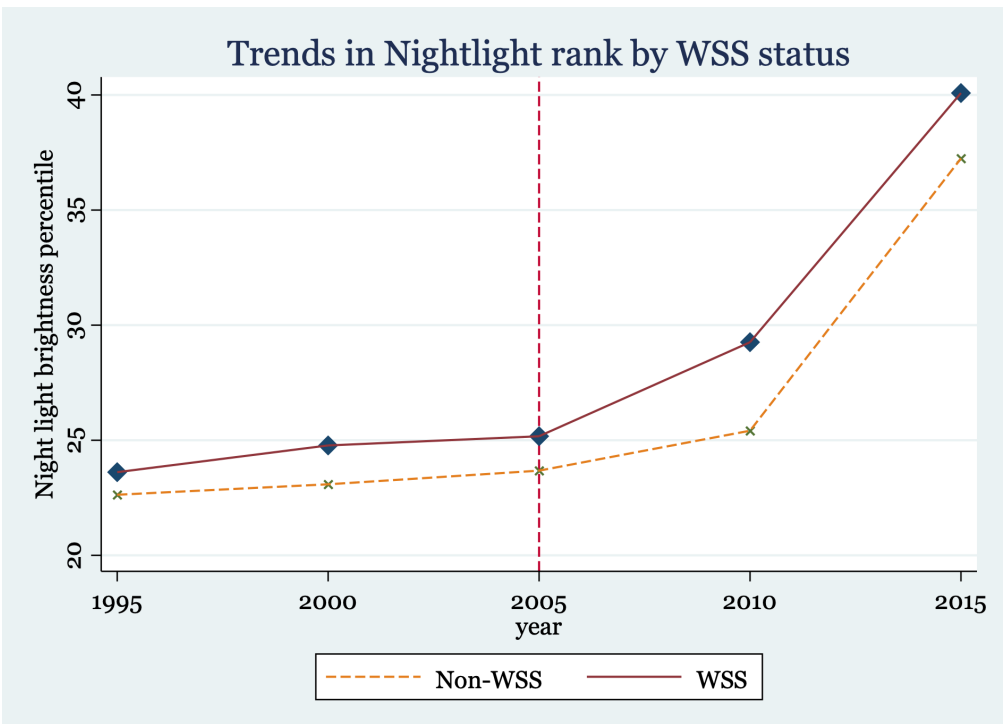

Notes: Figures shows trends in night light ranks across WSS program and non-program wards. Ward average night light index converted into a percentile rank to permit cross year comparisons.

Second, we show trends in night light percentile rank data to explore the plausibility of our main identification assumption. The existence of multiple rounds of night light data before 2005 permits an examination of parallel trends between WSS program and non-program wards. Figure 4 shows the trajectory of night light average rank across these groups between 1995 and 2015. Consistent with the fact that they are more likely to be urban, WSS wards have a higher night night light average rank in 1995. Importantly for our purposes, the trend between 1995 and 2005 for each group is more or less parallel.

While the two pieces of evidence above are supportive of the plausibility of the parallel trends assumption, they are not definitive. The key trend to validate our estimates is support for CCM and not the night light index. The moderate and statistically significant correlation of -0.27 between nightlight rank and CCM support in 2000 is not high enough to rule out non-parallel trends in vote share. Secondly, while differences in observables are limited and/or small, this design cannot account for differences in time-varying unobservables. 
We address these lingering concerns in three ways. First and as summarized in equation 2, we include a range of controls and especially their interactions with Elections $_{j}$ to capture potential differential trends in support for CCM. As shown in Table 3, program wards are more urban and are less likely to have an uncontested council election in 2000. Thus our controls $U_{i}$ include an indicator for urban status and any uncontested election within the parent ward. In addition, we include a set of region indicators $\sum$ Region $_{i}$ interacted with Elections $_{j}$ to capture differential trends in support for CCM. These additional controls capture recent political dynamics, in particular, the growth in support for opposition parties in urban areas and particular regions of the country. 60

$Y_{i j}=\beta_{0}+\sum \gamma_{j} *$ Election $_{j}+\sum \beta_{j} D_{i} *$ Election $_{j}+\sum \delta_{j} * U_{i} *$ Election $_{j}+\sum \lambda_{j} *$ Region $_{i} *$ Election $_{j}+\varepsilon_{i j}$

Our second strategy addresses concerns that our estimates are confounded by the effects of other contemporaneous government programs in WSS wards. We examine the robustness of our key estimates to controlling for other contemporaneous public goods provided in program wards. We leverage the community module of the 2008/9 National Panel Survey which identifies primary school construction to be the second most important activity communities are engaged in. ${ }^{61}$ We construct an indicator for primary school construction during the 20062010 period from EMIS data and include a set of interactions with Elections $s_{j}$ to specifications 1 and 2. We also use a ward level panel of night lights ranks to capture a broad range of other government programs including electrification and/or other industrial policy interventions that could potentially confound the results.

Our third and final strategy uses a machine driven matching strategy combined with the

\footnotetext{
${ }^{60}$ Controlling for differential trends across rural/urban areas and regions has also been shown to improve the consistency of estimates of $\beta_{j}$. See Dube and Vargas 2013; Bazzi and Gudgeon 2018 for a discussion of the estimate properties associated with adjusting for regional trends

${ }^{61}$ Importantly, there was no increase in primary school construction during the period of study (Figure C.5 in the Appendix).
} 
difference-in-difference approach above to estimate the key parameters. ${ }^{62}$ In theory, using matched WSS and non-WSS wards enhances the plausibility of the parallel trends assumption. We implement the matching algorithm as follows. ${ }^{63}$ After an initial normalized differences comparison between WSS and non-WSS wards, we estimate a machine selected logit model to generate a propensity score. We trim the sample symmetrically at the top and bottom of the propensity score to restrict the comparison to wards on a common support. We repeat the normalized difference comparison using the trimmed sample to examine balance properties. One advantage of this approach is the possibility to test for the plausibility of the unconfoundedness assumption using a lagged dependent variable. ${ }^{64}$ Having established improvements in the comparability of the groups, we use nearest neighbor matching to generate difference-in-differences estimates of $\beta_{2005}, \beta_{2010}$ and $\beta_{2015}$.

For each set of results we present, we explore impact heterogeneity by whether the ward had any preexisting secondary schools in 2000. We hypothesize that the marginal benefit of a new secondary school is considerably higher when it is the first secondary school in any given ward, and that the experience of older secondary schools likely anchors expectations about the quality of the new school.

\section{Results}

In Table 4 we present the results of estimating specifications 1 and 2. Standard errors in all specifications are clustered at the district level. Column (1) corresponds to specification 1 above, column (2) includes a urban and uncontested indicators fully interacted with Elections $_{j}$, while column(3) adds region indicators interacted with Elections ${ }_{j}{ }^{65}$ Our pre-

\footnotetext{
${ }^{62}$ See Imbens 2015 for a description of this estimation technique

${ }^{63}$ More details are available in Appendix B

${ }^{64}$ Given the timing of the WSS policy intervention, there should be no effect of the intervention on lagged outcome variables such as CCM support in 2000.

${ }^{65}$ Estimating vote share in uncontested elections after 2000, particularly in splitting wards, requires a few assumptions. As we explain in the appendix A, we assume 100 percent vote share for the elected candidate and impute the number of votes cast in these uncontested wards using district averages for contested wards that share the same rural/urban status
} 
ferred estimate comes from column (3) which accounts for differential trends across urban wards and Tanzania's regions. The estimates in column (3) suggest that the announcement effect $\left(\beta_{2005}\right)$ is statistically significant and positive. CCM candidates gain about 1.9 percentage points in WSS wards relative to non-WSS wards. The point estimate for $\beta_{2010}$, the immediate post-implementation effect, has the opposite sign and is also statistically significant at the 10 percent level. Contrary to the announcement effect, support for CCM candidates in WSS wards is 1.4 percentage points lower. The implementation penalty doesn't appear to last very long. Our estimate for $\beta_{2015}$ is negative, small and statistically indistinguishable from zero.

\section{[Table 4 About Here]}

We explore impact heterogeneity by estimating specifications separately for wards with and without secondary schools in 2000. The results for wards with no school are shown in Columns (4)-(6) while columns (7)-(9) present electoral impacts for wards with at least one school in 2000. Our preferred estimates for each of these populations is drawn from columns (6) and (9). There is a clear difference in the pattern of announcement gains and implementation costs between these groups. Our estimate of $\beta_{2005}$ in wards with no schools is slightly larger than in column (3), a 2.3 percentage point gain. However, the estimate of $\beta_{2010}$ in the same wards is negative, very small and statistically insignificant. In wards with at least one school in 2000, our estimate for $\beta_{2005}$ corresponds to an imprecisely estimated gain of 2.3 percentage points while our estimate for $\beta_{2010}$ represents a statistically significant large penalty of 4.1 percentage points. A plausible interpretation is that in wards with no prior schools, the gains from announcement are short-lived and there are no real penalties from implementation. In other words, the benefits of novel access to a school outweighed the associated costs. Conversely, for wards with pre-existing schools, the costs exceeded experienced benefits inducing a large penalty in $2010 .{ }^{66}$

\footnotetext{
${ }^{66}$ This aligns with de Kadt and Lieberman (2017) finding that exposure of public services ratchets up citizens' expectations and/or reveals official corruption - thereby depressing incumbents' electoral support.
} 
Our results suggest that electoral sanctions are limited to the most proximate elections in 2010 and do not extend beyond one election cycle. Overall our estimates for $\beta_{2015}$ in both the full and sub- samples suggest a small, negative and statistically insignificant effect. The point estimate in column (9) suggests a potential residual penalty of just under 1 percentage point, but this estimate is imprecise.

[Table 5 About Here]

In Table 5 we present results that condition for contemporaneous primary school construction. Our preferred specifications in columns (3), (6) and (9) suggest that the estimates from Table 4 are robust to controlling for primary school construction. The announcement effect is positive and significant across all specifications. However, the post implementation effect in column (3) is negative, smaller and imprecise. Nevertheless, the post implementation effect in wards with an existing school (column(9)) is negative, substantive and statistically significant. Notably, we observe a negative effect of primary school construction in the 2005, 2010 and 2015 elections (columns (3), (6), and (9)). These point estimates, combined with the fact that there was no significant increase in primary school construction during the period under study (Figure C.5 in Appendix C) add confidence to our interpretation of the electoral impacts of the WSS policy.

To rule out the possibility that our results are driven by other targeted programs, we estimate specifications 1 and 2 with night lights index rank as the dependent variable. Night lights have been used in the literature to capture broad changes in economic development associated with electrification and/or general expansion of economic activities. ${ }^{67}$ Table 6 presents these results where we condition on primary school construction. The sign and significance of estimates in Table 6 are opposite those observed for CCM vote share in Tables 4 and 5. Estimates, in the full and split samples, are negative and statistically indistinguishable from zero for the announcement effect and generally positive and borderline significant for the implementation effect.

\footnotetext{
${ }^{67}$ Henderson, Storeygard and Weil 2008
} 
In Table 7 , we restrict the sample of wards to those that never split throughout the study period. Examining electoral effects in non-splitting wards allows us to disentangle the potential additional net benefits of ward splitting from the WSS policy. The results in column(3) suggest a similar positive and significant announcement effect as in Table 4. If anything, the point estimate is larger ranging between 2.4 and 3 percentage points. The implementation effect is still negative but smaller and insignificant. However, the pattern of heterogeneity in implementation penalties is consistent with our earlier results. In wards with secondary schools prior to the policy announcement there is a nearly 3 percentage point penalty (albeit imprecisely estimated with a p-value of 0.101).

Finally, we present matched estimates in Table 8 . The results of this exercise are much less precise but are consistent with the pattern of our earlier results. The announcement result in column (2) is positive, of similar magnitude to the results in Table 4 and significant at the 10 percent level. The overall implementation effect estimated here has the wrong sign. However, an examination of heterogeneity in columns (3) and (4) confirms the earlier patterns we observed. There is an electoral penalty of nearly 4 percentage points in wards with an existing school (significant at the 10 percent level). Of note is the large, positive and significant post-implementation effect that is appreciably different from the null estimated in Table 4. The other 2015 estimates in the trimmed samples in columns (2)-(4) are all positive, but not significant. 
Table 3: Selected Characteristics of WSS Program and Non-WSS Program Wards

\begin{tabular}{|c|c|c|c|c|c|}
\hline & $\begin{array}{c}(1) \\
\text { Non-WSS }\end{array}$ & $\begin{array}{c}(2) \\
\text { WSS Wards }\end{array}$ & $\begin{array}{c}(3) \\
\text { Overall }\end{array}$ & $\begin{array}{c}(4) \\
\text { p-value }\end{array}$ & $\begin{array}{l}(5) \\
N\end{array}$ \\
\hline Total Turnout per household, 2000 & $\begin{array}{l}8.444 \\
(0.336)\end{array}$ & $\begin{array}{c}9.395 \\
(0.311)\end{array}$ & $\begin{array}{c}9.080 \\
(0.236)\end{array}$ & 0.058 & 2401 \\
\hline CCM Vote Share, 2000 & $\begin{array}{l}0.741 \\
(0.007)\end{array}$ & $\begin{array}{c}0.724 \\
(0.005)\end{array}$ & $\begin{array}{c}0.729 \\
(0.004)\end{array}$ & 0.030 & 2520 \\
\hline CHADEMA Vote Share, 2000 & $\begin{array}{l}0.236 \\
(0.018)\end{array}$ & $\begin{array}{c}0.214 \\
(0.011)\end{array}$ & $\begin{array}{c}0.221 \\
(0.010)\end{array}$ & 0.301 & 403 \\
\hline Share of Wards Uncontested, 2000 & $\begin{array}{l}0.216 \\
(0.014)\end{array}$ & $\begin{array}{c}0.185 \\
(0.009)\end{array}$ & $\begin{array}{c}0.195 \\
(0.008)\end{array}$ & 0.058 & 2523 \\
\hline Number of Secondary Schools, 2000 & $\begin{array}{l}0.345 \\
(0.021)\end{array}$ & $\begin{array}{c}0.299 \\
(0.015)\end{array}$ & $\begin{array}{c}0.314 \\
(0.012)\end{array}$ & 0.073 & 2523 \\
\hline Percentile rank night light index, 1995 & $\begin{array}{l}22.708 \\
(1.324)\end{array}$ & $\begin{array}{l}23.318 \\
(0.938)\end{array}$ & $\begin{array}{l}23.116 \\
(0.765)\end{array}$ & 0.708 & 2471 \\
\hline Percentile rank night light index, 2000 & $\begin{array}{l}23.163 \\
(1.330)\end{array}$ & $\begin{array}{l}24.506 \\
(0.947)\end{array}$ & $\begin{array}{l}24.062 \\
(0.771)\end{array}$ & 0.412 & 2471 \\
\hline Percentile rank night light index, 2005 & $\begin{array}{l}23.748 \\
(1.324)\end{array}$ & $\begin{array}{l}24.937 \\
(0.939)\end{array}$ & $\begin{array}{l}24.544 \\
(0.766)\end{array}$ & 0.465 & 2471 \\
\hline Share urban/peri-urban & $\begin{array}{l}0.236 \\
(0.015)\end{array}$ & $\begin{array}{c}0.265 \\
(0.011)\end{array}$ & $\begin{array}{c}0.255 \\
(0.009)\end{array}$ & 0.112 & 2523 \\
\hline Ward Area & $\begin{array}{l}0.029 \\
(0.003)\end{array}$ & $\begin{array}{c}0.028 \\
(0.001)\end{array}$ & $\begin{array}{c}0.028 \\
(0.001)\end{array}$ & 0.629 & 2431 \\
\hline Elevation Range, meters & $\begin{array}{l}377.876 \\
(14.958)\end{array}$ & $\begin{array}{c}364.369 \\
(10.025)\end{array}$ & $\begin{array}{c}368.836 \\
(8.336)\end{array}$ & 0.446 & 2431 \\
\hline Mean Elevation, meters & $\begin{array}{l}1042.059 \\
(17.627)\end{array}$ & $\begin{array}{c}1026.924 \\
(12.338)\end{array}$ & $\begin{array}{c}1031.929 \\
(10.107)\end{array}$ & 0.481 & 2431 \\
\hline Number of Households, 2002 & $\begin{array}{l}410.980 \\
(16.466)\end{array}$ & $\begin{array}{l}503.258 \\
(14.645)\end{array}$ & $\begin{array}{l}472.678 \\
(11.242)\end{array}$ & 0.000 & 2402 \\
\hline Share of hhlds below poverty line, 2002 & $\begin{array}{l}0.352 \\
(0.007)\end{array}$ & $\begin{array}{c}0.353 \\
(0.005)\end{array}$ & $\begin{array}{c}0.352 \\
(0.004)\end{array}$ & 0.967 & 2374 \\
\hline Unprotected well for water, 2002 & $\begin{array}{l}0.274 \\
(0.012)\end{array}$ & $\begin{array}{c}0.288 \\
(0.008)\end{array}$ & $\begin{array}{c}0.283 \\
(0.007)\end{array}$ & 0.344 & 2402 \\
\hline Electricity used for lighting, 2002 & $\begin{array}{l}0.084 \\
(0.007)\end{array}$ & $\begin{array}{c}0.075 \\
(0.004)\end{array}$ & $\begin{array}{c}0.078 \\
(0.004)\end{array}$ & 0.260 & 2402 \\
\hline Owns radio or telephone, 2002 & $\begin{array}{l}0.536 \\
(0.006)\end{array}$ & $\begin{array}{c}0.532 \\
(0.004)\end{array}$ & $\begin{array}{c}0.533 \\
(0.004)\end{array}$ & 0.592 & 2402 \\
\hline Ward-level Illiteracy Rate, 2002 & $\begin{array}{l}0.366 \\
(0.006)\end{array}$ & $\begin{array}{c}0.378 \\
(0.004)\end{array}$ & $\begin{array}{c}0.374 \\
(0.003)\end{array}$ & 0.104 & 2402 \\
\hline Dependency Ratio, 2002 & $\begin{array}{l}1.759 \\
(0.015) \\
\end{array}$ & $\begin{array}{c}1.723 \\
(0.010)\end{array}$ & $\begin{array}{c}1.735 \\
(0.008)\end{array}$ & 0.035 & 2402 \\
\hline$N$ & 832 & 1691 & 2523 & & \\
\hline
\end{tabular}

Standard errors in parentheses. Selected attributes either measured at/before 2000 or aggregated to ward boundaries in 2000, are drawn from various administrative data sets including the National Electoral Commission, 2002 Population Census and the Education Management Information System. WSS wards defined as wards where a secondary school was constructed and started operation between 2006 and 2010. P-values (column (4)) are from a null hypothesis of equality of WSS and non-WSS wards. 


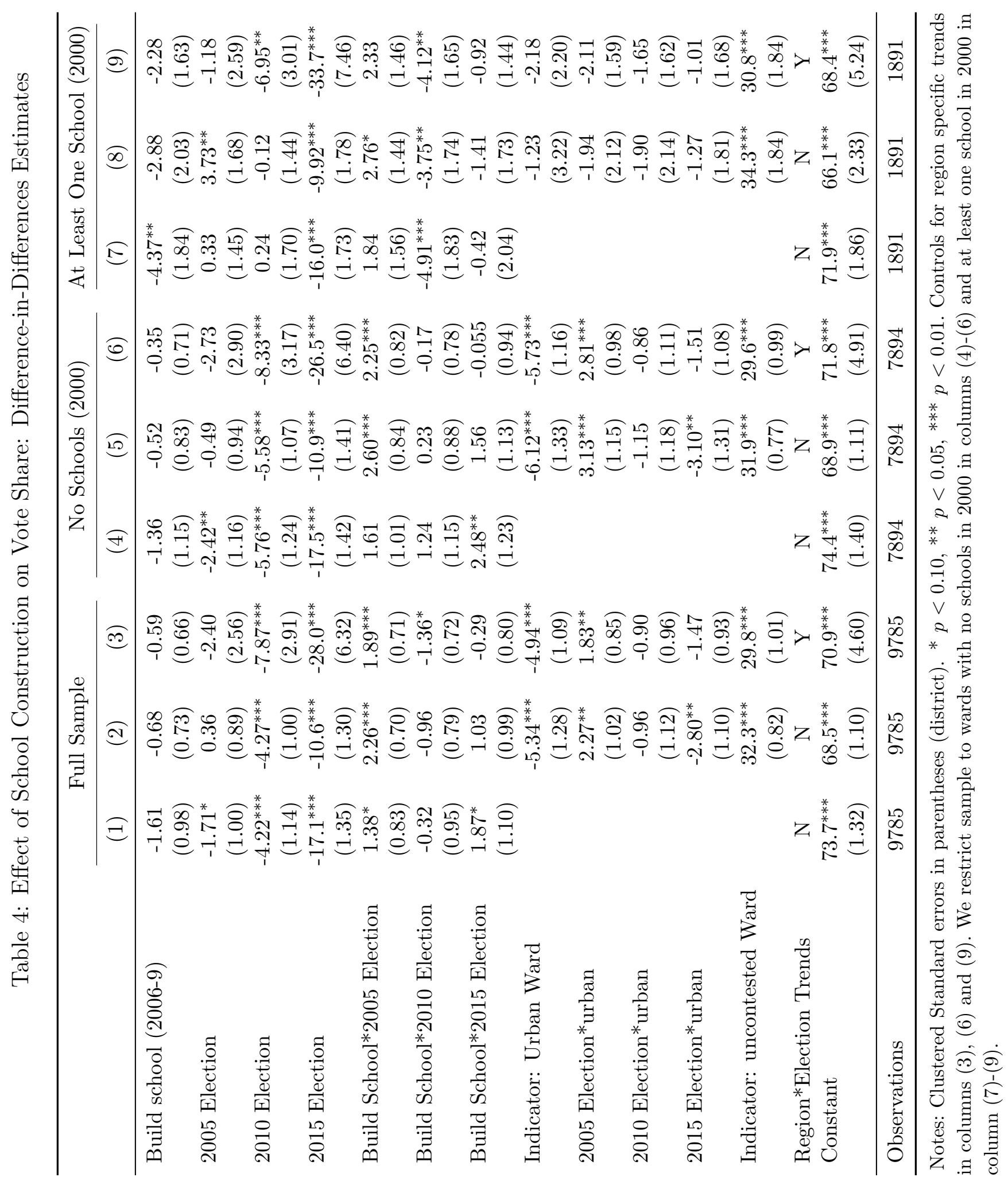




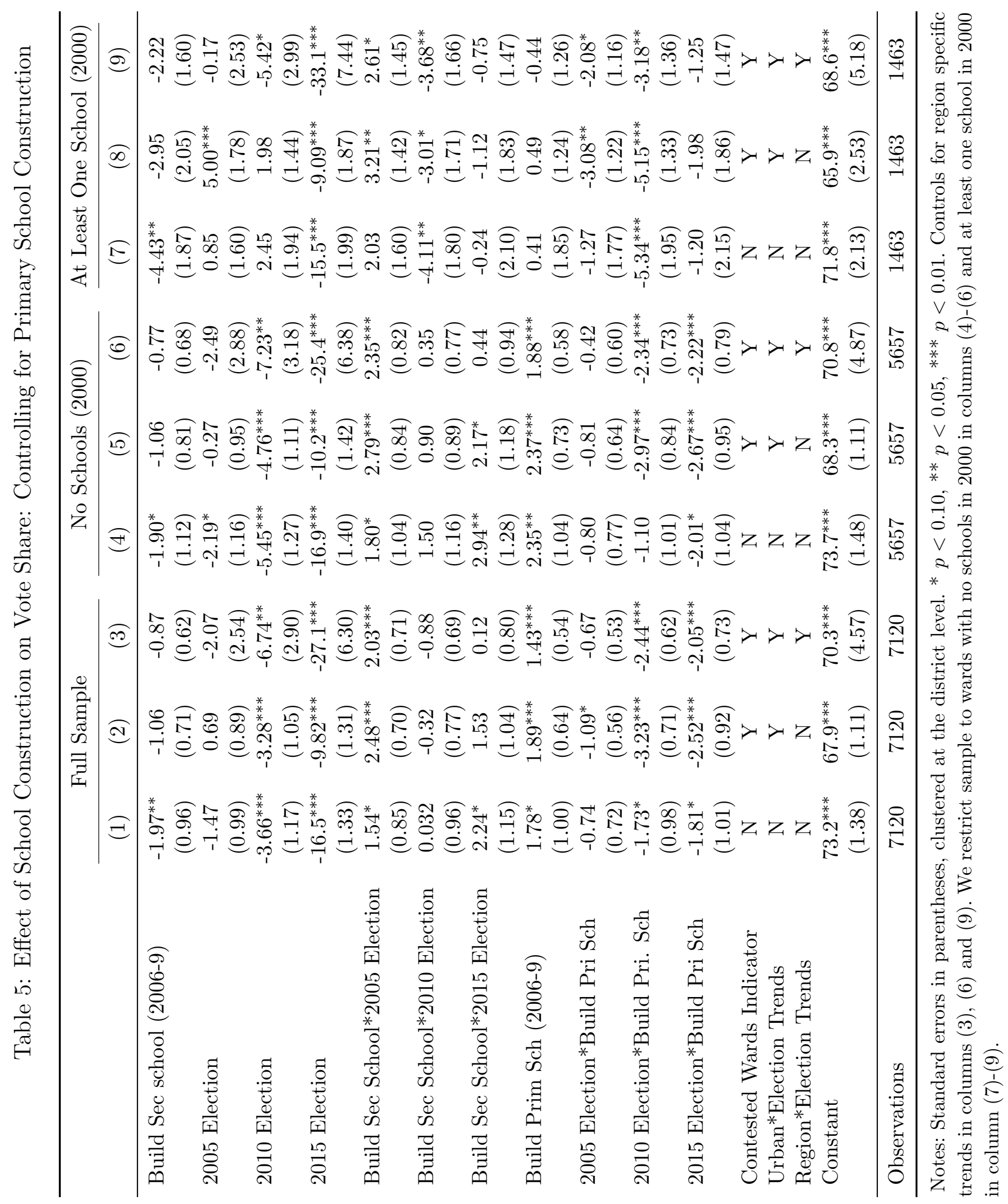




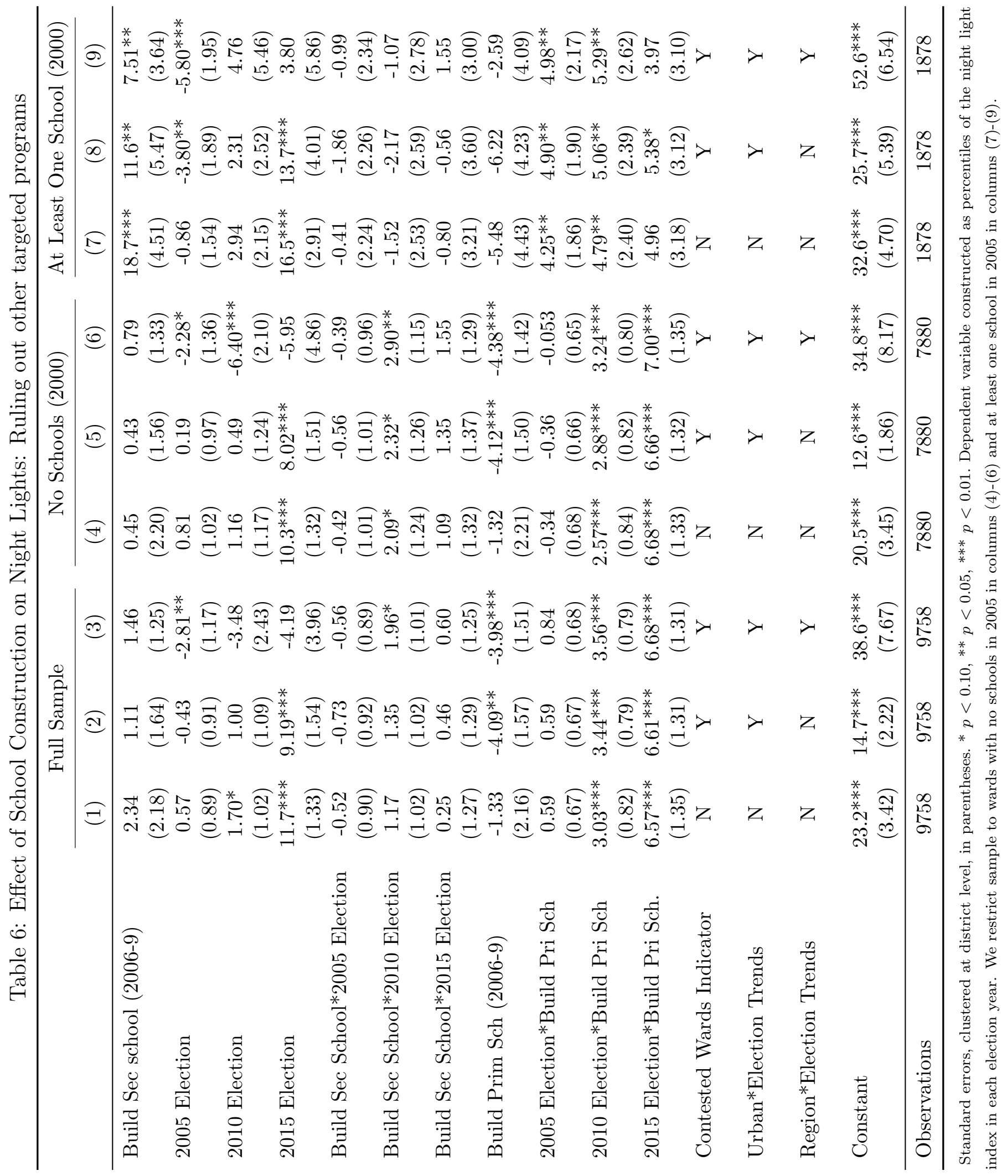




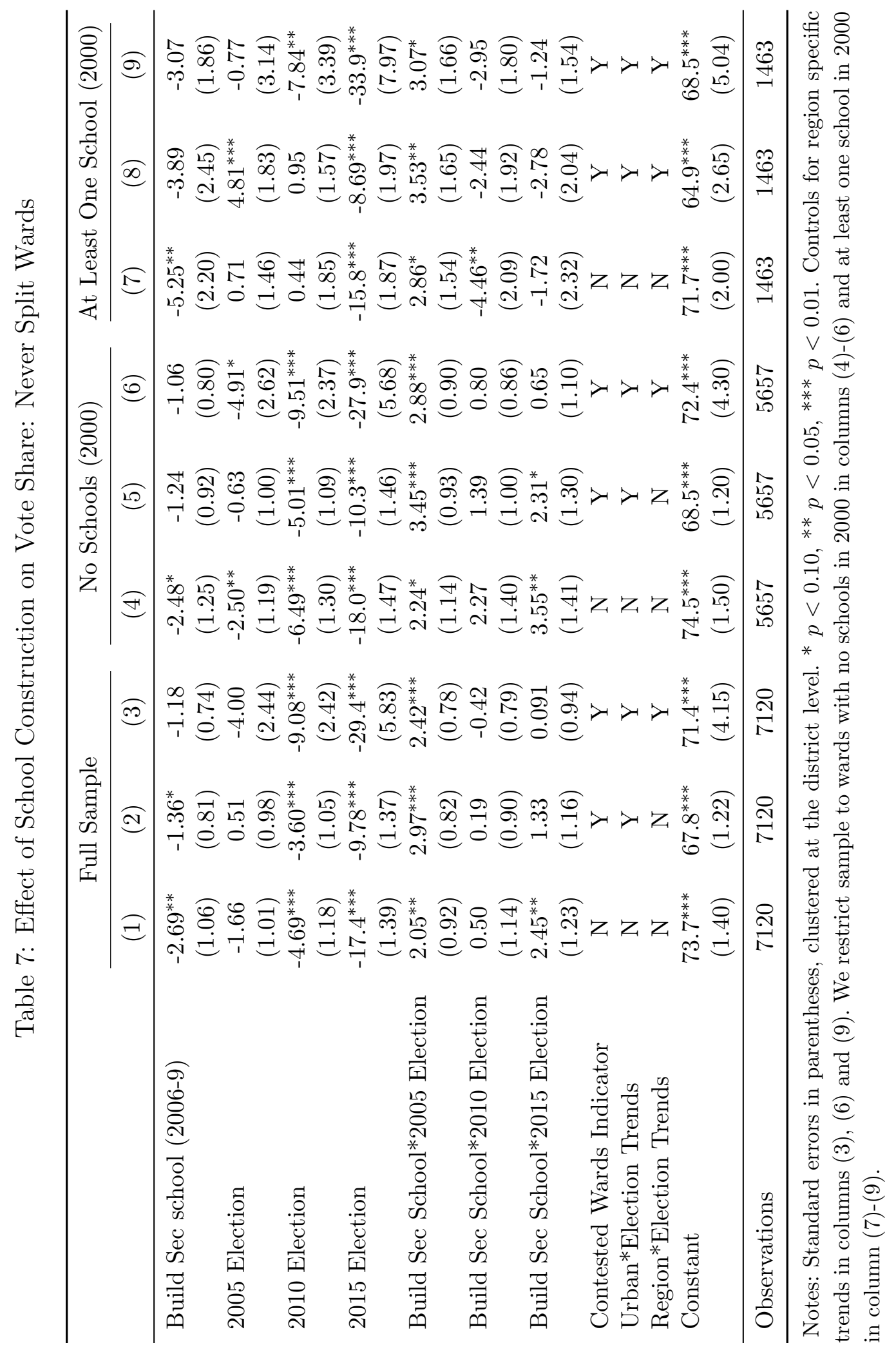


Table 8: Matching Estimates: Impact of School Construction on $\Delta$ Vote Share

\begin{tabular}{lcccc}
\hline & $(1)$ & $(2)$ & $(3)$ & $(4)$ \\
& Full Sample & Trimmed Sample & No School & $>1$ School \\
\hline ATT: 2005 & $3.21^{* * *}$ & $1.96^{*}$ & 2.03 & -1.41 \\
& $(1.116)$ & $(1.162)$ & $(1.430)$ & $(1.791)$ \\
\hline Observations & 2334 & 2087 & 1515 & 572 \\
\hline & & & & \\
ATT:2010 & 1.61 & 1.58 & $3.32^{*}$ & $-4.08^{*}$ \\
& $(1.128)$ & $(1.282)$ & $(1.785)$ & $(2.124)$ \\
\hline Observations & 2331 & 2084 & 1513 & 571 \\
\hline & & & & \\
ATT:2015 & $1.43^{*}$ & 1.43 & 1.32 & 0.12 \\
& $(0.831)$ & $(1.036)$ & $(1.296)$ & $(1.597)$ \\
\hline Observations & 2334 & 2087 & 1515 & 572 \\
Trimming & $\mathrm{N}$ & $\mathrm{Y}$ & $\mathrm{Y}$ & $\mathrm{Y}$ \\
\hline
\end{tabular}

Standard errors in parentheses, clustered at the district level. ${ }^{*} p<0.10,{ }^{* *} p<0.05$, *** $p<0.01$. Table reports nearest neighbor matching average treatment on the treated (ATT) estimates for effect of school construction on CCM Vote share in each of the subsequent elections. Column (1) uses the untrimmed full sample, while columns (2)-(4) drop all wards with propensity scores less than 0.1 or great than 0.9 . Column (3) restricts the sample to wards with no school in 2000, while column (4) restricts sample to wards with at least one school in 2000.

\section{Discussion}

\subsection{Community Contributions: Survey Evidence}

In this section we provide evidence that (a) a large scale school building program took place after 2005 that involved community participation; and (b) this program represented a significant economic burden for the communities involved. Figure 5 shows both the scale of the WSS program and associated community-level costs. The data are from Tanzania's National Panel Survey (TZNPS), administered between 2008-2009 and covering 3,280 households in 410 Enumeration Areas. ${ }^{68}$ Here, too, we limit our analysis to 349 Enumeration Areas on the

\footnotetext{
${ }^{68}$ The Tanzania National Panel Survey is a nationally-representative household survey which provides measures of poverty, agricultural yields, and other key development indicators.
} 
mainland. The survey questionnaire listed 14 investment project types. The panel on the left in Figure 5 shows community-level reports of incidence of projects (2007-2008), while the right graph shows the average community contribution by project type.

Figure 5: Contributions to Community Projects
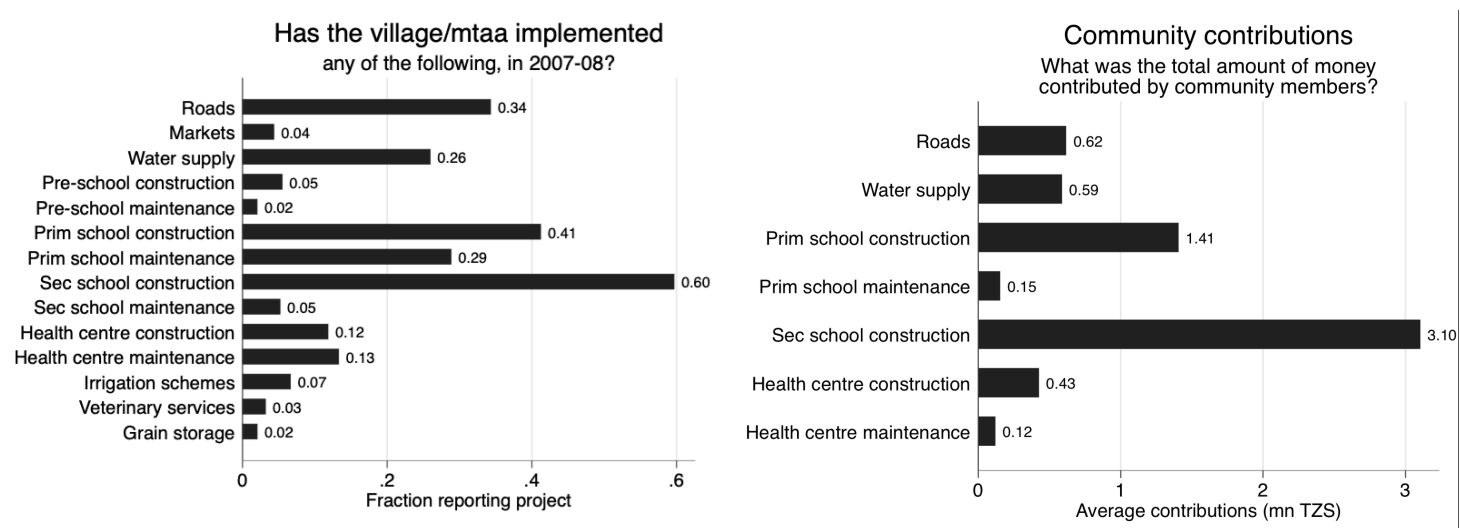

Source: National Panel Survey 2008-09, Community Data. The graphs show the scale (left) and communitylevel costs (right) of the WSS policy.

To reiterate the extraordinary scale of the WSS program, 60 percent of communities in the TZNPS reported building a secondary school, making it the most reported activity. Primary school construction was reported by 41 percent of communities. Recall that there was no uptick in primary school construction during this period (Figure C.5 in Appendix C) comparable to secondary school construction. Among communities that reported any investment project, 71 percent reported building a secondary school (not shown in the figure). On average, contributions to secondary school construction projects amounted to $3.1 \mathrm{mn}$ TZS (about $\$ 1,340$ ) - more than twice the cost of the next highest project by contributions and about six times the community contribution for the average project. In the sample, the median earnings for wage earners and non-farm self-employed were 50,000 TZS and 72,000 TZS, respectively. Therefore, at about 36,000 TZS per household, the mean secondary school contributed was about half of monthly cash income. ${ }^{69}$

\footnotetext{
${ }^{69}$ We use the average cluster size of 86 households in the 2012 Census as the denominator in our estimates.
} 


\subsection{Electoral Returns of Quality Signals?}

We noted above that implementation of the WSS policy revealed a bundle of signals to Tanzanians, including deterioration in learning outcomes. In this section we explore whether improvements in learning outcomes after 2013 explain ward-level CCM vote share in 2015. We noted above that following a precipitous fall in CSEE pass rates (Figure 2), the government initiated the Big Results Now! (BRN) program designed to improve learning outcomes. Introduced in 2013, BRN reforms were motivated in part by a national outcry about falling exam performance. We evaluate a key aspect of the reform that recognized high performing schools, a designation that is a potentially powerful treatment for any school, but especially for those new schools with a very short examinations record.

Figure 6: BRN Impact Unconfoundedness Test

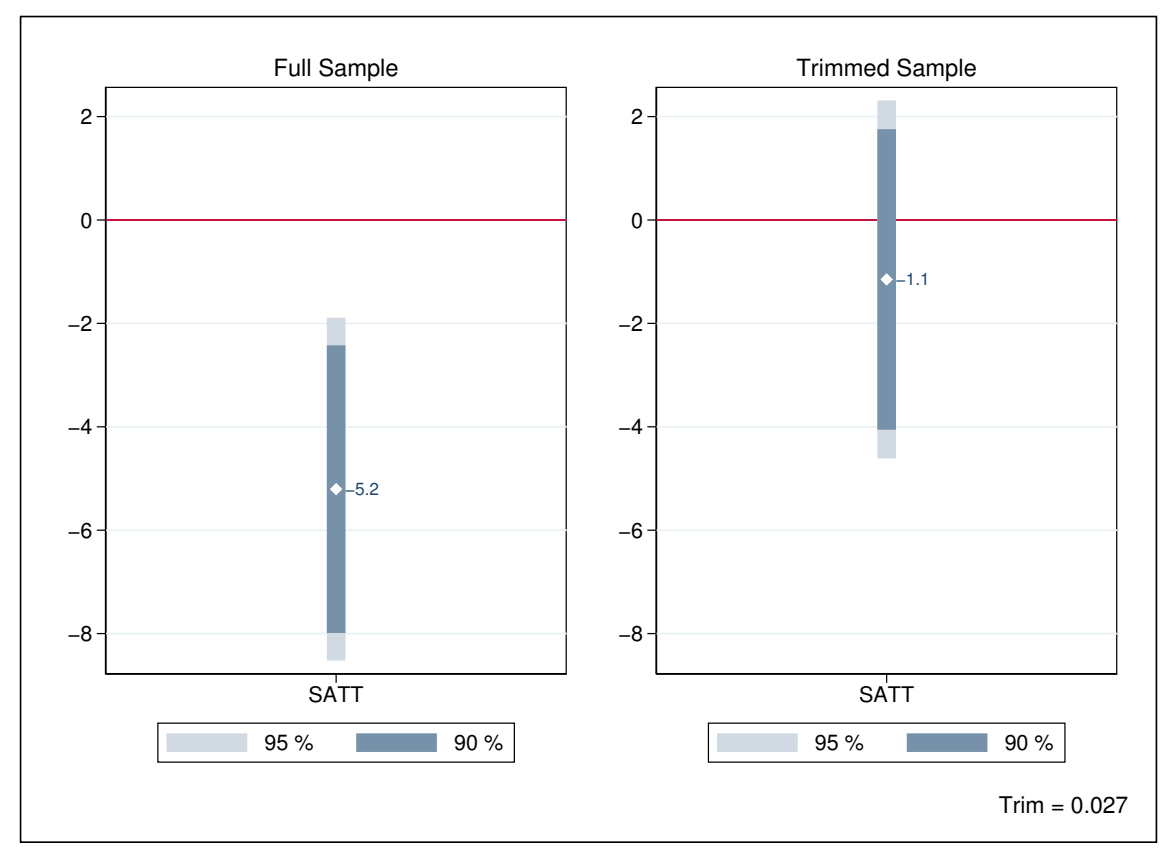

Notes: Outcome is change in CCM support between 2005 and 2010. Shaded strip around point estimate corresponds to $90 / 95$ confidence intervals. BRN recognized wards are significantly different in the full sample.

In particular, we examine if being nationally recognized in any of the two years (2013, 2014) before the 2015 election, is associated with gains in ward-level CCM vote share. Using NECTA data we code the top 100 schools (in terms of average exam score improvement) in 
either of the two years before the 2015 election. We then use the matching methods described in Appendix B to estimate the effect of information about local school quality of electoral outcomes in the 2015 election. Figure 6 shows that recognized wards are predominantly those where support for CCM has been falling (between 2005 and 2010). BRN recognized wards tend to be wealthier and are more likely to have had at least one existing secondary schools (in 2000). The left panel shows this effect starkly, with a pseudo treatment effect of about -5 percentage points, significant at the 1 percent level. Trimming the sample to improve comparability reduces this effect by nearly 80 percent. However, while it is no longer statistically significant, the point estimate of just over -1 percentage point, is suggestive that this empirical strategy fails to balance treated and non-treated wards.

Table 9: Impact of Learning About School Quality of Electoral Outcomes

\begin{tabular}{lcccc}
\hline & Full Sample & Trimmed Sample & WSS Ward & Non-WSS Ward \\
\hline SATT & -1.93 & -1.89 & -1.57 & -4.94 \\
& $(1.53)$ & $(1.66)$ & $(1.75)$ & $(4.14)$ \\
\hline Observations & 2331 & 1881 & 1290 & 591 \\
Trimming & $\mathrm{N}$ & $\mathrm{Y}$ & $\mathrm{Y}$ & $\mathrm{Y}$ \\
\hline
\end{tabular}

Standard errors in parentheses, clustered at the district level. ${ }^{*} p<0.10,{ }^{* *} p<0.05,{ }^{* * *}$ $p<0.01$. Table reports nearest neighbor matching average treatment on the treated (ATT) estimates for effect of BRN school recognition program on the change in CCM Vote Share between 2010 and 2015. Column (1) uses the untrimmed full sample, while columns (2)-(4) drop all wards with propensity scores less than 0.03 or great than 0.97 . Column (3) restricts the sample to wards exposed to the WSS program, while column (4) restricts sample to non-WSS wards.

Table 9 summarizes the effects of BRN on CCM vote share (2010-2015). Consistent with the unconfoundedness test above, all point estimates are negative and very imprecise. Underlying the low precision is the very small number of wards recognized under BRN. Out of a possible 2523 wards, only 169 wards are eligble for BRN recognition in either of the two years prior to the 2015 election. The difference in effects between "new" schools (WSS Wards) and schools with a longer performance record (Non-WSS Ward) has the right sign, but is (unsurprisingly) imprecise. ${ }^{70}$

\footnotetext{
${ }^{70}$ Notably, these findings are consistent with Stasavage and Harding (2014), who find that voters are more likely to reward visible and attributable investments in access over learning outcomes.
} 


\section{Conclusion}

Policy design, implementation, and public feedback is often a complex process involving multiple stages that span multiple electoral periods. Each stage typically reveals information that shapes public opinion and vote choice. A policy may be unpopular at announcement, but then gain popular support upon implementation after voters learn of its benefits through experience. The reverse can also be true. This calls for temporally-dynamic analyses of how voters respond to programmatic policies. As noted above, existing works on dynamic policy feedback largely focus on high-income established democracies. ${ }^{71}$ We contend that similar dynamics exist in low-income states, and show the existence of cyclical electoral impacts of a programmatic policy in Tanzania. To do this, we marshal a diverse array of data to examine, over multiple election cycles, the electoral impacts of a programmatic policy implemented to increase access to secondary education. We find that the policy resulted in an electoral bump of about 2 percentage points for the incumbent party in the first electoral cycle (2005), a penalty of -1.4 percentage points in the second cycle (2010), and no discernible effect in the third cycle (2015).

Our findings call for a nuanced understanding of the political economy of programmatic policies in low-income states. In these contexts, poor design, fiscal constraints, and lack of bureaucratic capacity are likely to introduce uncertainty during implementation, and generate heterogeneous electoral responses to programmatic policies, over time. In addition, experience with government programs may reveal information about corruption or ratchet up citizens' expectations in a manner that depresses support for incumbent parties and candidates. ${ }^{72}$ With this in mind, the ongoing expansion of the scope of programmatic policies in low-income states presents opportunities for longitudinal studies not only of their efficacy, but also their cyclical impacts on public opinion and political behavior. ${ }^{73}$

\footnotetext{
${ }^{71}$ Patashnik and Zelizer (2013); Jacobs and Mettler (2018)

${ }^{72}$ de Kadt and Lieberman (2017); Kruks-Wisner (2018)

${ }^{73}$ For instance, we show in Appendix $C$ that, like Tanzania, several African countries are in the midst of expanding public investments in education, among other sectors.
} 


\section{References}

Ahlerup, Pelle, Thushyanthan Baskaran and Arne Bigsten. 2015. "Tax Innovations and Public Revenues in Sub-Saharan Africa." Journal of Development Studies 51(6):689-706.

Albertus, Michael. 2012. "Vote Buying With Multiple Distributive Goods." Comparative Political Studies 46(9):1082-1111.

Babeiya, Edwin. 2011. "Multiparty Elections and Party Support in Tanzania." Journal of Asian and African Studies 47(1):83-100.

Baldwin, Kate. 2013. "Why Vote With the Chief? Political Connections and Public Goods Provision in Zambia." American Journal of Political Science 57(4):794-809.

Barrera-Osorio, Felipe, Pierre De Galbert, James Habyarimana and Shwetlena Sabarwal. 2019. "The Impact of Public-Private Partnerships on Private School Performance: Evidence from a Randomized Controlled Trial in Uganda." Economic Development and Cultural Change 68(2):429-469.

Baskaran, Thushyanthan, Brian Min and Yogesh Uppal. 2015. "Election cycles and electricity provision: Evidence from a quasi-experiment with Indian special elections." Journal of Public Economics 126:64-73.

Bazzi, Samuel and Matthew Gudgeon. 2018. "The Political Boundaries of Ethnic Divisions." NBER Working Paper, No. 24625.

Beland, Daniel. 2010. "Reconsidering Policy Feedback: How Policies Affect Politics." Administration and Society 42(5):568-590.

Billing, Trey. 2019. "Government Fragmentation, Administrative Capacity, and Public Goods: The Negative Consequences of Reform in Burkina Faso." Political Research Quarterly 73(2):669685.

Blimpo, Moussa, Justice Tei Mensah, Ken Ochieng' Opalo and Ruifan Shi. 2018. "Electricity Provision and Tax Mobilization in Africa." World Bank Policy Research Working Paper, 8408 .

Bold, Tessa, Deon Filmer, Gayle Martin, Ezequiel Molina, Brian Stacy, Christophe Rockmore, Jakob Svensson and Waly Wane. 2017. "Enrollment without Learning: Teacher Effort, Knowledge, and Skill in Primary Schools in Africa." Journal of Economic Perspectives 31(4):185-204.

Campbell, Andrea. 2003. How Policies Make Citizens: Senior Political Activism and the American Welfare State. Princeton, NJ: Princeton University Press.

Cilliers, Jacobus, Isacc M. Mbiti and Andrew Zeitlin. 2020. "Can Public Rankings Improve School Performance? Evidence from a Nationwide Reform in Tanzania." Journal of Human Resources pp. 1-46. 
Croke, Kevin. 2015. "Tools of Single Party Hegemony in Tanzania: Evidence From Surveys and Survey Experiments." Democratization 24(2):189-208.

D'Arcy, Michelle. 2013. "Non-State Actors and Universal Services in Tanzania and Lesotho: State-Building by Alliance." Journal of Modern African Studies 51(2):219-247.

Dasgupta, Aditya and Devesh Kapur. forthcoming. "The Political Economy of Bureaucratic Overload: Evidence from Rural Development Officials in India." American Political Science Review .

de Kadt, Daniel and Evan S. Lieberman. 2017. "Nuanced Accountability: Voter Responses to Service Delivery in Southern Africa." British Journal of Political Science pp. 1-31.

De la O, Anna. 2012. "Do Conditional Cash Transfers Affect Electoral Behavior? Evidence from a Randomized Experiment in Mexico." American Journal of Political Science $57(1): 1-14$.

Diaz-Cayeros, Alberto, Beatriz Magaloni and Federico Estevez. 2016. The Political Logic of Poverty Relief: Electoral Strategies and Social Policy in Mexico. New York, NY: .

Dionne, Kim Yi and Jeremy Horowitz. 2016. "The Political Effects of Agricultural Subsidies in Africa: Evidence from Malawi." World Development 87:215-226.

Dube, Oeindrila and Juan F. Vargas. 2013. "Commodity Price Shocks and Civil Conflict: Evidence from Colombia." Review of Economic Studies 80(4):13841421.

Easterly, William. 2009. "How the Millennium Development Goals are Unfair to Africa." World Development 37(1):26-35.

Golden, Miriam and Brian Min. 2013. "Distributive Politics Around the World." Annual Review of Political Science 16:73-99.

Grossman, Guy and Janet I. Lewis. 2014. "Administrative Unit Proliferation." American Political Science Review 108.

Harding, Robin. 2015. "Attribution and Accountability: Voting for Roads in Ghana." World Politics 67(4):656-689.

Henderson, J. Vernon, Adam Storeygard and David N. Weil. 2008. "Measuring Economic Growth from Outer Space." American Economic Review 102(2):994-1028.

Hicken, Allen. 2011. "Clientelism.” Annual Review of Political Science 14:289-310.

Imai, Kosuke, Gary King and Carlos Velasco Rivera. 2020. "Do Nonpartisan Programmatic Policies Have Partisan Electoral Effects? Evidence from Two Large-Scale Experiments." Journal of Politics 82(2):714-730.

Imbens, Guido W. 2015. "Matching Methods in Practice: Three Examples." Journal of Human Resources 50(2):373-419. 
Jacobs, Alan M. and R. Kent Weaver. 2014. "When Policies Undo Themselves: SelfUndermining Feedback as a Source of Policy Change." Governance 28(4):441-457.

Jacobs, Lawrence R. and Suzanne Mettler. 2018. "When and How New Policy Creates New Politics: Examining the Feedback Effects of the Affordable Care Act on Public Opinion." Perspectives on Politics 16(2):345-363.

Kambuga, Yusuph. 2013. "The Role of Community Participation in the Ongoing Construction of Ward Based Secondary Schools: Lessons for Tanzania." International Journal of Educatio and Research 1(7):1-10.

Kasara, Kimuli and Pavithra Suryanarayan. 2015. "When Do the Rich Vote Less Than the Poor and Why? Explaining Turnout Inequality Across the World." American Journal of Political Science 59(3):613-627.

Kilama, Blandina, Wietze Lindeboom and Roy van der Weide. 2006. "Where are the Poor in Tanzania? Methodology Paper.".

Kramon, Eric and Daniel Posner. 2016. "Ethnic Favoratism in Education in Kenya." Quarterly Journal of Political Science 11(1):1-58.

Kruks-Wisner, Gabrielle. 2018. Claiming the State: Active Citizenship and Social Welfare in Rural India. Cambridge, UK: Cambridge University Press.

Lagomarsino, Gina, Alice Garabrant, Atikah Adyas, Richard Muga and Nathaniel Otoo. 2012. "Moving Towards Universal Health Coverage: Health Insurance Reforms in Nine Developing Countries in Africa and Asia.".

Languille, Sonia. 2014. Secondary Education Expansion in Tanzania, 2004-2012: A Political Economy Perspective PhD thesis School of Oriental and African Studies London, UK: .

Languille, Sonia. 2019. "The Politics of the Education Budget: Financing Mass Secondary Education in Tanzania (2004-2012)." International Journal of Education Development 66:96-104.

Lee, Kenneth, Edward Miguel, Carson Christiano, Francis Meyo, Matthew Podolsky, Javier Rosa and Catherine Wolfram. 2016. "Electrification for Under Grid Households in Rural Kenya." Development Engineering 1:26-35.

Linberg, Staffan and Keith Weghorst. 2013. "What Drives the Swing Voter in Africa?" American Journal of Political Science 57(3):717-734.

Mafuru, Wilhelm L. 2011. Coping with Inadequacy: Understanding the Effects of Central Teacher Recruitment in Six Ward Secondary Schools in Tanzania PhD thesis University of Groningen Leiden, The Netherlands: .

Magaloni, Beatriz. 2006. Voting for Autocracy: Hegemonic Party Survival and Its Demise in Mexico. Cambridge, UK: Cambridge University Press. 
Mani, Anandi and Sharun Mukand. 2007. "Democracy, Visibility and Public Good Provision." Journal of Development economics 83:506-529.

Mettler, Suzanne. 2005. Soldiers to Citizens: The G.I. Bill and the Making of the Greatest Generation. New York: Oxford University Press.

Molina, Jose. 2001. "The Electoral Effect of Underdevelopment: Government Turnover and its Causes in Latin American, Caribbean and Industrialized Countries." Electoral Studies 20:427-446.

Morrison, Kevin M. 2009. "Oil, Nontax Revenue, and the Redistributional Foundations of Regime Stability." 63(1):107-138.

Morse, Yonatan L. 2014. "Party Matters: The Institutional Origins of Competitive Hegemony in Tanzania." Democratization 21(4):655-677.

Opalo, Ken Ochieng'. 2019. Legislative Development in Africa: Politics and Post-Colonial Legacies. Cambridge, UK: Cambridge University Press.

Opalo, Ken Ochieng'. 2020. "The Politics of Social Protection in Africa: Public Opinion Evidence from Kenya on Cash Transfers." Working Paper.

Patashnik, Eric M. 2014. Reforms at Risk: What Happens After Major Policy Changes are Enacted. Princeton, NJ: Princeton University Press.

Patashnik, Eric M. and Julian E. Zelizer. 2013. "The Struggle to Remake Politics: Liberal Reform and the Limits of Policy Feedback in the Contemporary American State." Perspectives on Politics 11(4):1071-1987.

Pierson, Paul. 1993. "When Effect Becomes Cause: Policy Feedback and Political Change." World Politics 45(4):595-628.

Richards, John and Aidan R. Vining. 2015. "Universal primary education in low-income countries: The contributing role of national governance." International Journal of Education Development 40:174-182.

Saez, Lawrence and Aseema Sinha. 2010. "Political Cycles, Political Institutions and Public Expenditure in India, 1980-200." British Journal of Political Science 40(1):91-113.

Schattschneider, Elmer E. 1935. Politics, Pressures, and the Tariff: A Study of Free Private Enterprise in Pressure Politics, as Shown in the 1929-1930 Revision of the Tariff. New York: Prentice-Hall.

Schneider, Anne Larson and Helen Ingram. 1993. "Social Construction of Target Populations: Implications for Politics and Policy." American Political Science Review 87(2):33447.

Selbervik, Hilde. 2006. "PRSP in Tanzania: Do Mkukuta and the CCM Election Manifesto Pull in the same Direction?". 
Skocpol, Theda. 1992. Protecting soldiers and mothers: The political origins of social policy in the United States. Cambridge, MA: Belknap Press.

Soss, Joe. 1999. "Lessons of Welfare: Policy Design, Political Learning, and Political Action." American Political Science Review 93(2):36380.

Stasavage, David. 2005. "Democracy and Education Spending in Africa." American Political Science Review 49(2):343-358.

Stasavage, David and Robin Harding. 2014. "What Democracy Does (and Doesn't Do) for Basic Services: School Fees, School Inputs, and African Elections." Journal of Politics 76(1):229-245.

Stokes, Susan C., Thad Dunning, Marcelo Nazareno and Valeria Brusco. 2013. Brokers, Voters, and Clientelism: The Puzzle of Distributive Politics. Cambridge, UK: Cambridge University Press.

Sumra, Suleman and Joviter K. Katabaro. 2014. "Declining Quality of Education: Suggestions for Arresting and Reversing the Trend." Economic and Social Research Foundation Discussion Paper 63.

URT. 2001. Education Sector Development Program. United Republic of Tanzania.

URT. 2017. Basic Education Statistics in Tanzania. United Republic of Tanzania.

Wantchekon, Leonard. 2003. "Clientilism and Voting Behavior: Evidence from a Field Experiment in Benin." World Politics 55(3):399-422.

Williams, Martin. 2017. "The Political Economy of Unfinished Development Projects: Corruption, Clientelism, or Collective Choice?" American Political Science Review 111(4):705-723.

World Bank. 2004. Program Document, Report No: 27631. Washington, DC: World Bank Group. 


\section{The Cyclical Electoral Effects of Programmatic Policies: Evidence From Secondary School Construction in Tanzania Supplementary Materials}

\section{A Constructing the Dataset}

The dataset that is used in this analysis is the result of linking our own and data from four different administrative sources over the four election cycles between 2000 and 2015. In this section, we detail the particular steps that we took to generate the greatest coverage that we could, both across mainland Tanzania and over the four election cycles. The five sources are as follows:

1. National Electoral Commission (NEC) that administers elections in Tanzania. We use ward council election data for all four elections in 2000, 2005, 2010 and 2015. The first major task involved is to transcribe pdf based records into machine readable data.

2. National Examinations Council of Tanzania (NECTA)- administers national examinations at the end of the primary and secondary school cycles. Annual data at the school level is available between 2011 and 2015.

3. Education and Management Information System (EMIS) - a system for collating the results of an annual school census. Data is only available for 2016.

4. National Population Census data for 2002 and 2012. We use three key derivatives from this data. First, we use the small area poverty estimates generated by Hoogevens et al (2005) to construct 'baseline' ward level measures of poverty. Secondly, we use the Geographic Information System maps for both the 2002 and 2012 census to address the challenges of linking wards over time between 2000 and 2010.

5. As a result of additional ward splitting between 2010 and 2015, we commissioned additional work to generate Geographic Information System map to link wards between 2010 and 2015

There are a number of challenges associated with constructing a balanced panel of wards some of which are generic to administrative data and some of which are peculiar to the agency and/or context. For instance the absence of a clean, uniform identification system for schools or wards across all sources is a common challenge that must be overcome when working with administrative data. We address the uniform identification problem in the following ways:

1. Standardizing the naming of units across all data sources: This implies that while some wards may be referred to as "ABCDE Town Council" in one data set and "ABCDE TC" in another, we create a uniform structure for ward and school labels across all datasets. This involves extracting a wide range of qualifying words such as "Town", "Rural", "High", "School", "Secondary", "Saint", "St" and mapping them into a shorter list of labels. 
2. Sequential matching based on administrative units: While qualifying phrases such as "town council" or "secondary school" can be easily regularized, different agencies spell ward and school names differently. The same ward may be spelled as "Sokoni" in one dataset and as "Sokon" or "Sokooni" in other datasets. Given the absence of uniform spelling for ward/school names and the difficulty of regularizing thousands of such names, we proceed in two steps. First, we standardize region and district names which are considerably fewer in number and can be reliably used to validate a match. Second, we use string fuzzy matching algorithms to find the best match for schools/wards across two data sources. Regularizing region and district names considerably narrows the search space to find matches, since we can constrain all potential matches to be in the same district and region.

One of the features of the electoral landscape for ward positions in Tanzania is the high share of uncontested elections. Over the four electoral cycles, just over one third of councilor elections are uncontested. Uncontested wards are two and a half times less likely to be urban and consequently have higher poverty and illiteracy rates and lower access to electricity. The electoral commission records the name and party of the candidate in uncontested wards and records the total number of votes cast as zero. We use these two features to impute two key pieces of data that that are used throughout our analysis. Firstly, we assume a $100 \%$ vote share for this candidate in these uncontested elections. Second, we impute the total number of votes cast using the district average of ward councilor election turnout in the same election year. Finally, we show in the appendix, that our key results are not sensitive to the imputation assumptions used.

A key challenge to linking wards over this period in Tanzania is the proliferation of administrative/political units. As we document in the main text, at the beginning of the study period there are only 2523 wards in 2000, 2552 in 2005 and a big jump to 3333 in 2010 and 3944 in 2015. The proliferation of administrative units isn't a problem, per se, if additional information identifying parent wards (for wards that have ever been split) is available alongside current unit identifiers. In our particular case, while a subset of split wards will retain the same name or a close derivative of the mother ward name, there are many cases where splits produce unrelated identifiers and no additional information about the mother ward is available. While fuzzy matching can reproduce linkages where name changes are minor, we need an alternative strategy to deal with linkages where names have changed completely. Our strategy to deal with unrelated names relies on the following steps:

1. Using the GIS shape files from 2002, 2012 and commissioned for 2017, we overlay maps of wards in 2017 and 2012, and 2002 and 2017 to identify linkages over the two key periods with considerable unit proliferation. A link between split wards and their mother ward is identified through the overlap of the respective polygons in the shape files. Given missing cartographic information and/or poor cartography, theoretically unchanged polygons (non-split wards) may not perfectly overlap. We use a threshold of at least $50 \%$ of a polygons area to define a linkage. The GIS shape files are also useful since they also include two sets of ward identifiers that can be used to merge with administrative data from two different time periods. These text labels identify mother wards (in the earlier shape file) and child wards (in the more recent shape file). 
2. Use string matching algorithms across data sources to link wards. Care is taken to match records between the most recent dataset which will also have more unique observations and an earlier dataset with fewer records. For example there are 3944 wards in 2015 but only 3333 in 2010 . The resulting dataset includes matched (more details below on how this is defined) and unmatched records (typically representing newer administrative units with different naming conventions).

3. Drop the matched records from the resulting file and store the unmatched records in a temporary file

4. Use string matching algorithms to link records in this temporary unmatched records file and the linked GIS files described above. Since every linked observation in the overlapping GIS files has two text identifiers, we proceed by first identifying the most recent set of wards that are contained in the intersected GIS file using the most recent region, district and ward identifiers. We take the resulting set of matches and using the older identifiers identify the mother wards. We can then use a one-to-many merge to link the identified mother wards to the set of GIS-intersection matchable child wards.

5. Additional matches identified through this GIS-linking and string matching process are then added to the string matched records.

Before we enumerate the specific steps taken to merge all of the five sources of data together, we describe below the string matching algorithms used and the relevant thresholds used to define a good match. We use the user-augmented Stata command reclink2 to match ward/school names across data sources. For this analysis our main linking identifiers are region, district and ward names. We use the following weights 8, 4 and 10 for region, district and ward to ensure that the algorithm favors records with the same ward (and to a lesser extent region) names. Finally we specify a minimum score cutoff of the match quality of 0.65. A score of 1 represents a perfect match while a score of 0 represents perfectly bad match. Potential matches are only identified if they have minimum score greater than or equal to 0.65 (the routine uses a default of 0.6 ). The algorithm allows one to store the match score which can be used to order matches or directly inspect match quality. We inspect each set of matches produced and drop low quality matches.

We merge our datasets separately for the 2010-2015 and the 2000-2005 periods in the following order:

1. Following the regularization of geographic units and schools names described above, we use reclink to merge the two recent school-level NECTA (2011-2015) and EMIS (2016) datasets. The merged dataset includes records for 4,894 secondary schools and crucially includes the year that the school was registered to start providing educational services as well as the examination pass rates for all schools.

2. We then merge the 2015 electoral data with the merged NECTA-EMIS dataset. Our string matching algorithm can match 2927 of the 3944 wards with 2345 exact matches. We examine the matches produced by this process and drop observations with a match score less than 0.957 . We retain all observations that are not matched between these two datasets so as to maintain the universe of wards in 2015. 
3. Next, we merge the resulting merged file above (ELEC-2015-NECTA-EMIS) with electoral records from 2010. As a result of administrative unit proliferation between 2010 and 2015, this merge is between 3944 wards in 2015 and 3333 wards in 2010. As we describe above, first we use the string matching algorithm to match 3313 wards (3245 of which are exact matches). We then take the 631 unmatched 2015 wards and merge them with the intersection of shape files from 2017 and 2012. Crucially, this process relies on region, district and ward names from the population census based files. This merger is able to identify a further 469 matched wards. The resulting ELEC-2015-2010NECTA-EMIS dataset has a total of 162 out of 39442015 wards (just over 4\%) that do not have a 2010 parent.

4. We then repeat the process linking data sources for 2000 and 2005 . We begin by merging the data from the 2005 ward elections with poverty mapping data derived from the 2002 population census. This is a ward-level file in which housing and population attributes have been aggregated up to the ward level. We are able to match 2516 of the 2552 wards. Following a physical examination of matches, we drop all matches with a match score less than 0.89 .

5. We then merge the resulting file above to the 2000 ward elections using the string matching algorithm. The resulting dataset (ELEC-2005-2000-POV) matches 2471 of the 25522005 wards implying a total of 81 wards in 2005 that do not have a 2000 ward parent.

6. Finally, we turn to merging the linked files between 2015/2010 (ELEC-2015-2010NECTA-EMIS) and 2005/2000 (ELEC-2005-2000-POV) data sources. The initial string matching algorithm produces 2335 matched and 1609 unmatched wards. We take the 1609 unmatched 2015 ward records and follow the process described above to identify matches using the intersection of GIS shape files from 2017 and 2002. First, we identify 14782015 wards that are contained in the linked 2017-2002 GIS intersection data. Using the 2002 identifiers, we can observe 1051 unique 2002 mother wards. Using a one-tomany merge, we are able to match 1469 of 16092015 wards. Consequently, we are able to link 38042015 wards to 2005 wards implying a total of 1402015 wards with no 2005 ward parent.

This process generates an unbalanced panel of wards defined by each electoral year. Since our analysis is based on wards defined using 2000 ward boundaries, out of the total of 2523 2000 level wards,

- 2453 wards are observed across all four electoral periods.

- 28 wards cannot be linked to wards in 2005, 2010 and 2015.

- 4 wards can be linked to 2015 wards but not to 2005 or 2010 wards

- 38 wards can be linked to 2010 and 2015 wards but not to 2005 wards.

This process can be repeated for each election year to identify linked and unlinked wards. For the 2015 wards, we are able to fully link 3668 out of 3944 wards across all four elections. 
56 wards wards in 2010 cannot be linked at all; 57 wards linked in 2005 and 2010 cannot be linked either in 2000 or 2015; 70 wards can be linked to 2005 and 2010 but not 2000; and 93 wards can be linked to 2000 and 2010 but not 2005. For the 2010 wards, we are able to link 3232 out of 3333 wards. 82005 wards cannot be linked either backwards or forward; 39 wards can be linked to 2005 but not 2000 or 2015; 54 wards can be linked to 2005 and 2015 but not 2000 . Finally for the 2005 wards, we are able to fully match 2453 out of 2552 wards. 12015 ward cannot be linked backwards; 56 wards can be linked to 2010 and 2015 but not 2000; 4 parent wards in 2000 cannot be linked to child wards in 2005 and 2010; and 38 parent wards in 2000 can be linked to 2010 and 2015 but not to 2005. Tables B.1 and B.2 compare unmatched and matched wards along key dimensions relevant to the analysis performed here.

\section{B Matching Estimates}

Given the absence of any electoral data prior to 2000, our difference-in-differences estimates rely on a strong assumption of parallel trends. To address this potential weakness we use a machine driven nearest neighbor matching estimation strategy (Imbens 2015) that has a number of useful properties. ${ }^{1}$ Firstly, the selection of covariates for the propensity score estimation is independent of researcher bias and follows an algorithm. From a set of covariates proposed by the author, the machine implements a stepwise process to select both level and interacted covariates using a log likelihood ratio test threshold to select covariates. ${ }^{2}$ Secondly, the extent to which treated and untreated distributions are trimmed to produce them matched sample over the common support is also machine driven. Finally, this strategy permits us to judge the likelihood that this empirical strategy passes an unconfoundedness test that underlies non-experimental program evaluation. By examining the extent to which treatment has no effect on a well chosen set of pre-treatment outcomes in the matched sample, we can draw confidence in the final matched estimates in Table 7 above. Below we enumerate the steps and results of this estimation strategy. Following Imbens (2015) the estimation follows four main steps.

\section{B.1 Comparing Treated and Non-treated Wards}

The plausibility of the parallel trends assumption depends on the comparability of observable (and by assumption unobservable) determinants of the key outcomes examined. Table B.1 compares treated and non-treated wards in the full sample using administrative data from the 2002 census and NECTA as well as measures of night light intensity. Following, Imbens (2015) we report normalized differences to illustrate where there are substantive differences in covariates in addition to traditional measures of statistically significant differences. The first point to note is that there are few statistically significant differences between treated and untreated wards. Treated wards are larger, as measured by the number of households in the ward in the 2002 census, with just over 70 additional households compared to untreated

\footnotetext{
${ }^{1}$ Imbens, Guido W. 2015. "Matching Methods in Practice: Three Examples." Journal of Human Resources $50(2): 373419$

${ }^{2}$ Interacted covariates are derived from the list of selected level covariates
} 
wards. While statistically significant, this normalized difference is only on the order of 0.1 standard deviations. Unsurprisingly, treated wards have fewer secondary schools in 2000. Finally treated wards are less likely to be uncontested. This difference is also small in magnitude and only significant at the $10 \%$ level. All of the other comparisons including in the share of households below the poverty line, electricity access, radio ownership and education, are both statistically indistinguishable from each other and normalized differences are all below 0.07 standard deviations. It is important to emphasize that while there are no or small differences in observables, we are unable to say whether and how differences in unobservables undermine this estimation strategy.

Table B.1: Comparison of Treated and Untreated Wards in the Full Sample

\begin{tabular}{lcccccc}
\hline & No WSS & WSC & $\begin{array}{c}\text { Norm. } \\
\text { diff }\end{array}$ & p-value & $\begin{array}{c}\text { N: No } \\
\text { WSC }\end{array}$ & N: WSC \\
\hline Ward: Num of Households & 410.98 & 503.258 & .122 & 0 & 796 & 1606 \\
Total turnout/number of households & 11.734 & 12.04 & .015 & .633 & 783 & 1595 \\
Number of Primary Schools, 2000 & 2.357 & 2.554 & .079 & .008 & 832 & 1691 \\
Number of Primary Schools, 2005 & 2.879 & 3.342 & .161 & 0 & 832 & 1663 \\
Primary School Built 2000-5 & .335 & .444 & .157 & 0 & 832 & 1691 \\
Secondary School Built 2000-5 & .34 & .122 & -.354 & 0 & 832 & 1691 \\
Average Night light index, 2000 & 3.426 & 3.292 & -.009 & .77 & 823 & 1654 \\
Average Night light index, 2005 & 2.528 & 2.496 & -.003 & .932 & 823 & 1654 \\
Number of Secondary Schools, 2000 & .345 & .299 & -.054 & .073 & 832 & 1691 \\
Indicator for Urban area & .236 & .265 & .048 & .112 & 832 & 1691 \\
Share of households below poverty line & .352 & .353 & .001 & .967 & 788 & 1586 \\
Use of unprotected well as source of drink- .274 & .288 & .029 & .344 & 796 & 1606 \\
ing water & & & & & & \\
Electricity used for lighting & .084 & .075 & -.034 & .26 & 796 & 1606 \\
Household owns radio or telephone & .536 & .532 & -.016 & .592 & 796 & 1606 \\
Ward-level Illiteracy Rate & .366 & .378 & .05 & .104 & 796 & 1606 \\
Dependency Ratio & 1.759 & 1.723 & -.064 & .035 & 796 & 1606 \\
Highest education of any household mem- 6.728 & 6.666 & -.033 & .275 & 796 & 1606 \\
ber & & & & & & \\
Proportion of school age household mem- . .219 & .214 & -.04 & .19 & 796 & 1606 \\
bers in school & & & & & & \\
Household head paid employee & .107 & .109 & .008 & .794 & 796 & 1606 \\
Share of uncontested Wards, 2000 & .216 & .185 & -.056 & .058 & 832 & 1691 \\
CCM Vote Share, 2000 & 73.751 & 72.025 & -.063 & .036 & 819 & 1647 \\
\hline
\end{tabular}

We use the full sample of ward level observations and covariates to construct propensity of having a secondary school constructed. Covariates are drawn from administrative data (census, National Election Commission and National Examinations Council) as well as remote sensing data. Poverty share is calculated using small area estimates mapping household assets to consumption.

\section{B.2 Estimating the Propensity Score}

As we describe above, the propensity score is estimated using a machine driven selection of level and interacted covariates in a maximum likelihood logit model. The researcher has three broad choices in this process. First to determine the set of covariates that should be 
included in the logit model either because they explain the likelihood of treatment and/or the final outcomes. Based on our understanding of the program, we include the number of secondary schools in the ward in 2000, an indicator for secondary school construction between 2000 and 2005 (before the election), as well as CCM vote share in the 2000 elections. Second, the researcher creates a second list of covariates from which the machine driven stepwise regression process selects explanatory variables for the propensity score estimation. At each step of the process a log-likelihood ratio test is performed and covariates are retained if the test statistic exceeds 1 or 2.71 for the level and interacted variables respectively. The researcher can choose different thresholds depending on their priors about interaction effects. ${ }^{3}$ Using the propensity score generated by the selected specification, we trim the sample following the variance minimizing criteria suggested by Crump et al (2008).

The procedure yields a trim of 0.096 at the top and bottom of the propensity score distribution. We repeat the propensity score estimation procedure outlined above on this trimmed sample to examine the set of determinants of treatment status. The results in Table B.2 show the set of covariates that are selected by this propensity score estimation process for both the full and trimmed sample. Consistent with the nature of the program described in Section 3 of the paper, the results suggest that school construction was more likely in wards with no secondary schools, where there was unmet demand for schooling. Schools are also more likely to be built in urban areas where both demand and the ability to finance school construction is higher. School construction under this program is negatively correlated with the number of secondary schools available in 2000 but positively correlated with the number of primary schools prior to the 2005 elections. Further the point estimates on night light indices, poverty, share of households with access to electricity and ward level literacy rates are consistent with the implementation process we detail - capturing both demand and capacity to raise the local taxes. Crucially, it does not appear that support for CCM in 2000 is associated with school construction between 2006 and 2009.

Table B.2: Propensity Score Estimation for Secondary School Construction

\begin{tabular}{lll}
\hline Variable & Full Sample & Trimmed Sample \\
\hline Number of Secondary Schools in 2000 & $-0.97^{* * *}$ & $-0.75^{* * *}$ \\
& $(0.21)$ & $(0.22)$ \\
CCM Vote Share, 2000 & $0.022^{*}$ & -0.00087 \\
& $(0.013)$ & $(0.0039)$ \\
Secondary School Built 2000-5 & $-2.85^{* * *}$ & $-2.18^{* * *}$ \\
Share of HH below poverty line & $(0.19)$ & $(0.27)$ \\
Number of Primary Schools in Ward, 2005 & -0.23 & 0.027 \\
& $(0.28)$ & $(0.55)$ \\
Number of HH in Ward & $0.25^{* * *}$ & $0.36^{* * *}$ \\
& $(0.036)$ & $(0.065)$ \\
\hline
\end{tabular}

${ }^{3}$ We use the default settings shown above as they have been shown to perform relatively well across a number of applications

${ }^{4}$ Crump, Richard et al. 2008. "Nonparametric Tests for Treatment Effect Heterogeneity", Review of Economics and Statistics Vol. 90, No. 3, p.389-405 
Table B.2 - continued from previous page

\begin{tabular}{|c|c|c|}
\hline Variable & Full Sample & Trimmed Sample \\
\hline & $(0.00099)$ & $(0.00091)$ \\
\hline \multirow[t]{2}{*}{ Average Night light index in Ward, 2005} & $0.16^{*}$ & \\
\hline & $(0.093)$ & \\
\hline \multirow[t]{2}{*}{ Primary School Built 2000-5 } & $0.39^{* * *}$ & \\
\hline & $(0.12)$ & \\
\hline \multirow[t]{2}{*}{ Dependency Ratio } & 0.75 & $-0.81^{* *}$ \\
\hline & $(0.56)$ & $(0.34)$ \\
\hline \multirow[t]{2}{*}{ Total Votes Cast per HH, 2000} & 0.0014 & $0.042^{*}$ \\
\hline & $(0.0044)$ & $(0.022)$ \\
\hline \multirow[t]{2}{*}{ Electricity used for lighting } & -0.79 & 0.51 \\
\hline & $(0.67)$ & $(1.41)$ \\
\hline \multirow[t]{2}{*}{ Household head paid employee } & 0.82 & -0.48 \\
\hline & $(0.75)$ & $(0.76)$ \\
\hline \multirow[t]{2}{*}{ Household owns radio or telephone } & $-1.10^{* *}$ & \\
\hline & $(0.51)$ & \\
\hline \multirow[t]{2}{*}{ Urban } & $2.01^{* *}$ & $2.13^{* *}$ \\
\hline & $(0.86)$ & $(0.99)$ \\
\hline \multirow{2}{*}{$\begin{array}{l}\text { Secondary School Built } 2000-5 \times \text { Number of Sec- } \\
\text { ondary Schools in } 2000\end{array}$} & $1.55^{* * *}$ & $1.90^{* * *}$ \\
\hline & $(0.24)$ & $(0.26)$ \\
\hline \multirow{3}{*}{$\begin{array}{l}\text { Household head paid employee } \times \text { Secondary } \\
\text { School Built 2000-5 }\end{array}$} & $2.33^{*}$ & \\
\hline & & \\
\hline & $\begin{array}{l}(1.25) \\
0.64 * *\end{array}$ & \\
\hline Urban $\times$ Number of Secondary Schools in 2000 & $0.64^{2+1}$ & \\
\hline \multirow{2}{*}{$\begin{array}{l}\text { Total Votes Cast per HH, } 2000 \times \text { Number of HH } \\
\text { in Ward }\end{array}$} & $0.00014^{* * *}$ & $0.00020^{* * *}$ \\
\hline & $(0.000037)$ & $(0.000043)$ \\
\hline \multirow{2}{*}{$\begin{array}{l}\text { Number of Primary Schools in Ward, } 2005 \times \\
\text { Number of Secondary Schools in } 2000\end{array}$} & $-0.17^{* * *}$ & \\
\hline & $(0.037)$ & \\
\hline \multirow{2}{*}{$\begin{array}{l}\text { Number of Secondary Schools in } 2000 \times \text { Number } \\
\text { of Secondary Schools in } 2000\end{array}$} & $0.37^{* * *}$ & $0.36^{* * *}$ \\
\hline & $(0.098)$ & $(0.100)$ \\
\hline \multirow{2}{*}{$\begin{array}{l}\text { Average Night light index in Ward, } 2005 \times \text { Num- } \\
\text { ber of Primary Schools in Ward, } 2005\end{array}$} & $0.012^{* *}$ & \\
\hline & $(0.0046)$ & \\
\hline \multirow[t]{2}{*}{ Urban $\times$ Average Night light index in Ward, 2005} & $-0.23^{* *}$ & \\
\hline & $(0.093)$ & \\
\hline \multirow{2}{*}{$\begin{array}{l}\text { Household head paid employee } \times \text { No. of Sec. } \\
\text { Schools }(2000)\end{array}$} & $-1.32^{* *}$ & \\
\hline & $(0.64)$ & \\
\hline \multirow[t]{2}{*}{ Dependency Ratio $\times$ Number of $\mathrm{HH}$ in Ward } & $0.0013^{* * *}$ & $0.0012^{* *}$ \\
\hline & $(0.00042)$ & $(0.00054)$ \\
\hline \multirow[t]{2}{*}{ Urban $\times$ Dependency Ratio } & $-1.16^{* *}$ & $-0.98^{*}$ \\
\hline & $\mathrm{Co}$ & nued on next page \\
\hline
\end{tabular}


Table B.2 - continued from previous page

\begin{tabular}{lll}
\hline Variable & Full Sample & Trimmed Sample \\
\hline \multirow{2}{*}{ Dependency Ratio $\times$ CCM Vote Share, 2000 } & $(0.48)$ & $(0.55)$ \\
& $-0.015^{* *}$ & \\
& $(0.0070)$ &
\end{tabular}

Household owns radio or telephone $\times$ Number of $0.0016^{*}$

$\mathrm{HH}$ in Ward

Average Night light index in Ward, $2005 \times$ Sec- $0.049^{*}$

ondary School Built 2000-5

Number of Primary Schools in Ward, 2000

Average Night light index in Ward, 2000

$-0.019$

$(0.030)$

Number of Primary Schools in Ward, $2000 \times$ $-0.35^{* * *}$

Number of Secondary Schools in 2000

$(0.052)$

Average Night light index in Ward, $2000 \times$ Sec$0.055^{* * *}$ ondary School Built 2000-5

Average Night light index in Ward, $2000 \times$ Num$0.014^{* * *}$ ber of Primary Schools in Ward, 2005

$(0.0049)$

Number of Primary Schools in Ward, $2000 \times$ Sec$-0.24^{* * *}$ ondary School Built 2000-5

Share of HH below poverty line $\times$ Number of Primary Schools in Ward, 2000

Share of $\mathrm{HH}$ below poverty line $\times$ Number of $\mathrm{HH}$ in Ward

Average Night light index in Ward, $2000 \times$ Average Night light index in Ward, 2000

$-0.0020^{* * *}$

$(0.00058)$

Total Votes Cast per HH, $2000 \times$ CCM Vote $-0.00048^{* *}$

Share, 2000

$(0.00023)$

Household head paid employee $\times$ Number of $\mathrm{HH}$ $0.0028^{* *}$ in Ward

Average Night light index in Ward, $2000 \times$ Electricity used for lighting

Dependency Ratio $\times$ Number of Primary Schools $0.19^{* *}$ in Ward, 2000 
Table B.2 - continued from previous page

\begin{tabular}{lll}
\hline Variable & Full Sample & Trimmed Sample \\
\hline & & $(0.096)$ \\
Number of Primary Schools in Ward, 2000 $\times$ & $0.00013^{*}$ \\
Number of HH in Ward & \\
& & $(0.000079)$ \\
Urban $\times$ Electricity used for lightning & $-3.65^{* *}$ \\
Constant & & $(1.59)$ \\
& -0.43 & 1.20 \\
\hline Observations & $(1.08)$ & $(0.77)$ \\
\hline \hline
\end{tabular}

Notes: Clustered standard errors in parentheses. ${ }^{*} p<0.10,{ }^{* *} p<0.05,{ }^{* * *} p<0.01$. Column 1 shows the machine-driven list-wise selection of covariates to explain the likelihood that a school is constructed between 2006 and 2010 in the full sample. Column 2 shows logit estimates for selected covariates on a trimmed sample.

\section{B.3 Testing the Plausibility of the Unconfoundedness Assumption}

In this section we implement a test that uses the process defined above to estimate the effect of treatment on pre-treatment outcomes. Given the temporal order of treatment, secondary school construction should have no effect on pre-2005 electoral outcomes. While it is not possible to test the unconfoundedness assumption, estimates substantially and statistically close to zero provide confidence in the improvements promised by this estimation strategy (Imbens (2015)). This test partitions the set of pre-treatment variables into a set of pseudotreatment variables and a set of covariates that can be used to estimate the propensity score. We proceed in the following steps:

1. We define our pseudo-treatment variable to be the vote share for the CCM candidate in the 2000 councillor elections.

2. Using the stepwise regression process described above, we estimate the propensity to have a school constructed between 2006 and 2009 using the same thresholds for level and interacted variables described above.

3. We then use nearest neighbor matching to estimate the impacts of treatment on the treated on $2000 \mathrm{CCM}$ vote share. We show results of this test for two samples: the full sample of wards and a trimmed sample. Trimming is implemented using the guidance provided by Crump et al. (2008) in which the top and bottom 12 percent of the propensity score distributions are dropped from the sample.

4. To account for residual differences in the sample (see Table 2 in the paper on share of wards with schools constructed in the prior electoral cycle), we use regression adjustment using all of the matching variables to improve comparability. 
5. Every treated variable is matched to the nearest neighbor in the control group (with replacement). Finally, we report robust standard errors.

The results of this process are shown in Figure B.1.

Figure B.1: Testing the Plausibility of the Unconfoundedness Assumption

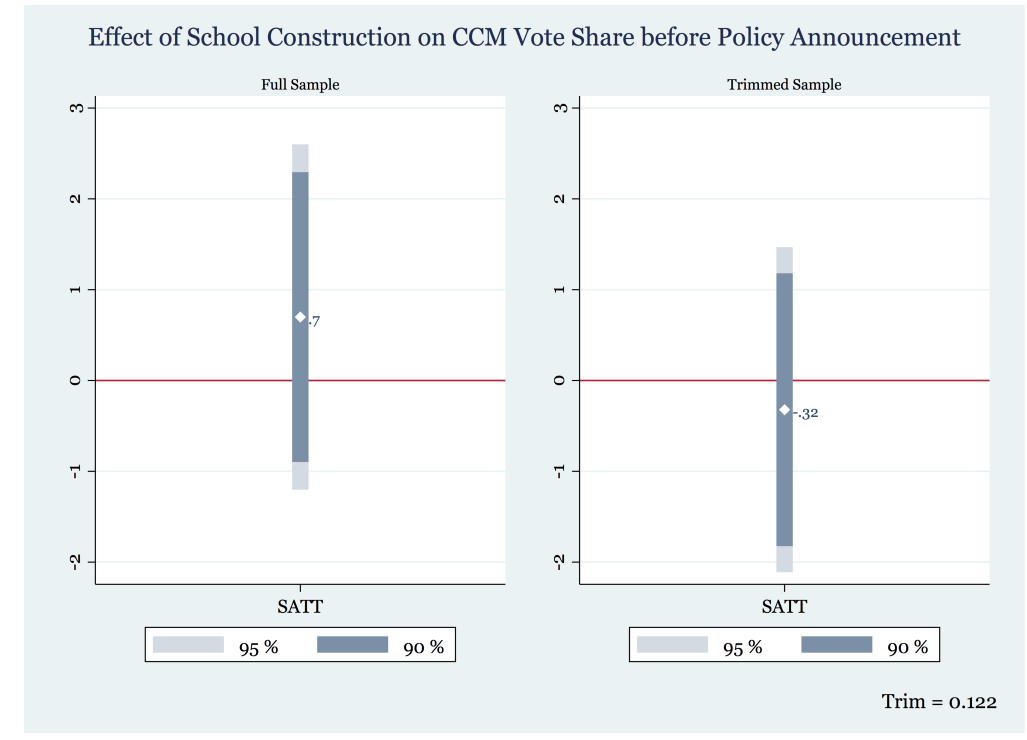

Figure B.2: Distribution of Propensity Score

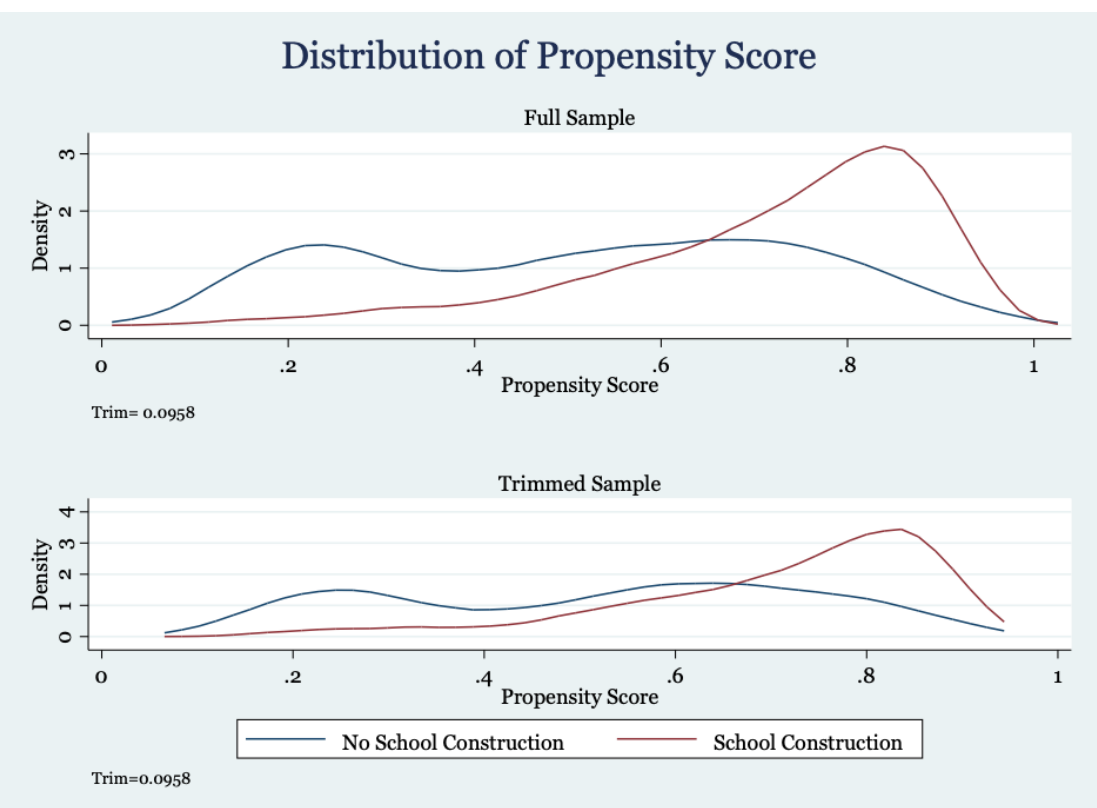

As the results in Figure B.1 suggest, both our estimates in the full (left panel) and trimmed sample (right panel) are substantively and statistically indistinguishable from zero. Importantly, even in the full sample, the effect of school construction on 2000 elections is 
Table B.3: Comparison of Treated and Untreated Wards in Trimmed Sample

\begin{tabular}{|c|c|c|c|c|c|c|}
\hline & No WSS & WSS & $\begin{array}{l}\text { Norm. } \\
\text { diff }\end{array}$ & $\mathrm{p}$-value & $\begin{array}{l}\text { N: No } \\
\text { WSS }\end{array}$ & $\mathrm{N}: \mathrm{WSC}$ \\
\hline Ward: Num of Households & 394.71 & 453.002 & .088 & .008 & 741 & 1346 \\
\hline Total turnout/number of households & 11.707 & 11.451 & -.013 & .689 & 741 & 1346 \\
\hline Number of Primary Schools, 2000 & 2.402 & 2.452 & .021 & .508 & 741 & 1346 \\
\hline Number of Primary Schools, 2005 & 2.896 & 3.079 & .068 & .034 & 741 & 1346 \\
\hline Primary School Built 2000-5 & .327 & .404 & .113 & 0 & 741 & 1346 \\
\hline Secondary School Built 2000-5 & .356 & .115 & -.386 & 0 & 741 & 1346 \\
\hline Average Night light index, 2000 & 3.376 & 2.637 & -.053 & .091 & 741 & 1346 \\
\hline Average Night light index, 2005 & 2.442 & 1.919 & -.047 & .139 & 741 & 1346 \\
\hline Number of Secondary Schools, 2000 & .363 & .31 & -.063 & .049 & 741 & 1346 \\
\hline Indicator for Urban area & .239 & .251 & .02 & .535 & 741 & 1346 \\
\hline Share of households below poverty line & .358 & .361 & .01 & .762 & 741 & 1346 \\
\hline $\begin{array}{l}\text { Use of unprotected well as source of drink- } \\
\text { ing water }\end{array}$ & .28 & .295 & .031 & .345 & 741 & 1346 \\
\hline Electricity used for lighting & .084 & .069 & -.059 & .061 & 741 & 1346 \\
\hline Household owns radio or telephone (yes $=1$ ) & .539 & .526 & -.052 & .11 & 741 & 1346 \\
\hline Ward-level Illiteracy Rate & .362 & .38 & .08 & .013 & 741 & 1346 \\
\hline Dependency Ratio & 1.765 & 1.74 & -.045 & .157 & 741 & 1346 \\
\hline $\begin{array}{l}\text { Highest education of any household mem- } \\
\text { ber }\end{array}$ & 6.759 & 6.626 & -.074 & .021 & 741 & 1346 \\
\hline $\begin{array}{l}\text { Proportion of school age household mem- } \\
\text { bers in school }\end{array}$ & .22 & .215 & -.046 & .153 & 741 & 1346 \\
\hline Household head paid employee & .106 & .103 & -.014 & .66 & 741 & 1346 \\
\hline Share of uncontested Wards, 2000 & .198 & .172 & -.049 & .129 & 741 & 1346 \\
\hline CCM Vote Share, 2000 & 73.882 & 72.249 & -.061 & .061 & 741 & 1346 \\
\hline
\end{tabular}

Sample is trimmed symmetrically using the optimal bound of 0.096. Covariates are drawn from administrative data (census, National Election Commission and National Examinations Council) as well as remote sensing data. Poverty share is calculated using small area estimates mapping household assets to consumption.

small and statistically indistinguishable from zero providing some confidence in the headline results of Table 3 in the main paper. The point estimate in the trimmed sample gets closer to zero suggesting a strong likelihood that the matching process implemented here addresses meaningful differences between WSC and non-WSC wards.

In Figure B.2 we illustrate the overlap in the estimated propensity score between treated and untreated wards. The top panel shows the full sample propensity score distribution, while the bottom panel shows the distribution after the trim factor of 0.096 is applied. As the figure shows, the range of propensity scores over which there is common support is broad and consistent with the results of Table B.2.

\section{B.4 Estimating Nearest Neighbor Matching Estimates}

Having established the plausibility of the unconfoundedness assumption required for the matching estimates, we return to estimating the average treatment on the treated wards for each of the election outcomes in 2005, 2010 and 2015 using the approach outlined in the section above. Results are in Table B.3. Specifically we: 
- We use ward councilor electoral outcomes for 2005, 2010 and 2015 as outcome variables

- Use the propensity score estimation results shown in Table B.2 and the trimming process suggested by Crump et al (2008) to improve comparability of the treated and non-treated wards. The trim level calculated using this method is 0.096 (Figure B.2).

- We repeat the comparison of treated and non-treated wards in Table 8 below for the trimmed sample. As the results suggest, trimming improves the comparability of the two groups with the most normalized differences getting smaller and with diminished statistical significance. There are two notable changes in the opposite direction. The difference in the share of wards building a secondary school between 2000 and 2005 increases in the trimmed sample.

- On account of persistent (albeit relatively small) differences, we report regression adjusted matching estimators in Table 7 in the paper. In particular, rather than report simple differences between a treated and its matched nearest neighbor, we use the covariates selected for the propensity score estimation to adjust for the remaining differences in observables between matched wards (Abadie et al (2004)). ${ }^{5}$ We report heteroskedasticity-consistent standard errors.

\section{Tanzania in Comparative Perspective}

While our study focuses on education in Tanzania, the lessons herein are applicable to other African states and in different policy areas. Since the early 1990s, many re-introduced multiparty electoral politics, which in turn created strong demand for programmatic policies in sectors as diverse as health, ${ }^{6}$ education, ${ }^{7}$ agriculture, ${ }^{8}$ infrastructure, ${ }^{9}$ and social protection. ${ }^{10}$. In response to increasing electoral competitiveness, promises to provide public goods and services became the currency of politics across the region.

With regard to education reforms, many African states mirror Tanzania's experience (Figures C.3 and C.4). Beginning in the mid-1990s, African states introduced universal primary education (UPE) policies. In most instances, UPE was adopted as an end in itself as part of the MDGs. Thus international targets (and donor funding) drove the realization

\footnotetext{
${ }^{5}$ Abadie, Alberto et al. 2004. "Implementing Matching Estimators for Average Treatment Effects in Stata" Stata Journal, Vol. 4, No. 3, p. 290311

${ }^{6}$ See Carbone, Giovanni. 2011. "Democratic Demands and Social Policies: The Politics of Health Reform in Ghana." Journal of Modern African Studies 49(3):381408; Dionne, Kim Yi. 2011. "The Role of Executive Time Horizons in State Response to AIDS in Africa." Comparative Political Studies 44(1):5577.

${ }^{7}$ See DArcy, Michelle. 2013. "Non-State Actors and Universal Services in Tanzania and Lesotho: StateBuilding by Alliance." Journal of Modern African Studies 51(2):219247; and Stasavage, David. 2005. "Democracy and Education Spending in Africa." American Political Science Review 49(2):343358

${ }^{8}$ Bates, Robert H. and Steven A. Block. 2013. "Revisiting African Agriculture: Institutional Change and Productivity Growth." Journal of Politics 75(2):371384.

${ }^{9}$ Harding, Robin. 2015. "Attribution and Accountability: Voting for Roads in Ghana." World Politics 67(4):656689; Briggs, Ryan C. 2012. "Electrifying the base? Aid and incumbent advantage in Ghana." Journal of Modern African Studies 50(4):603624

${ }^{10}$ Ferguson, James. 2015. Give a Man a Fish: Reflections on the New Politics of Distribution. Durham, NC: Duke University Press.
} 
Figure C.3: Trends in Gross Enrollment Across African States

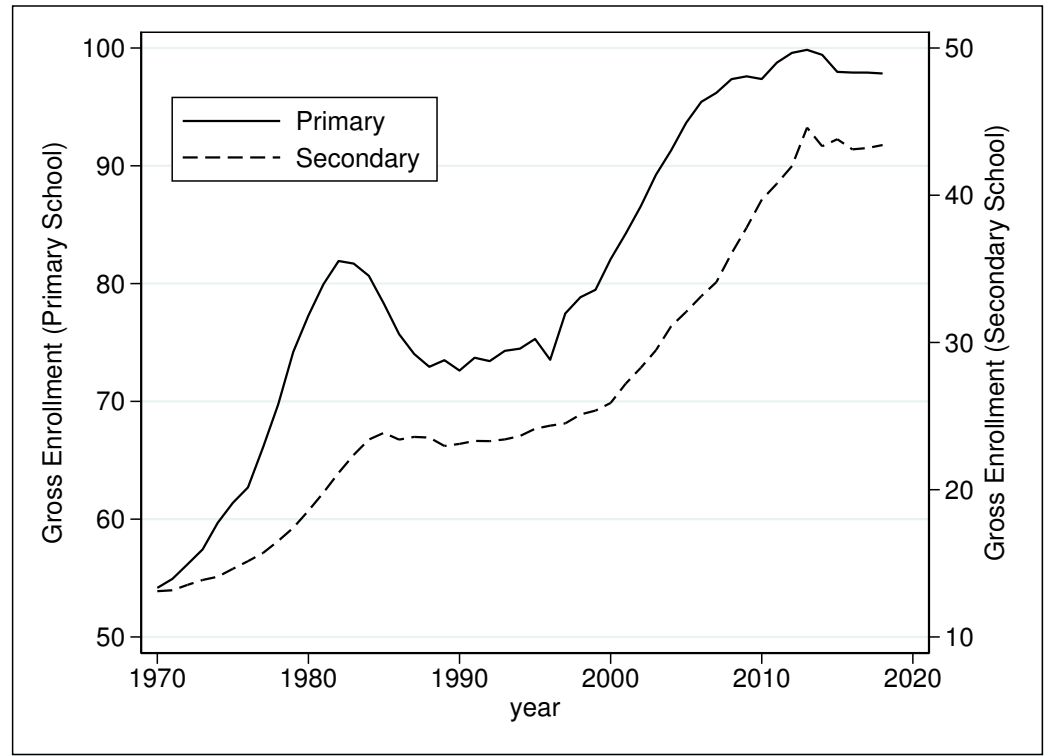

Trend lines indicate gross enrollment rates for primary and secondary schools in African states over time. Notice that secondary enrollment lags primary enrollment. Source: World Bank Indicators Dataset.

Figure C.4: Trends in Gross Enrollment in Tanzania

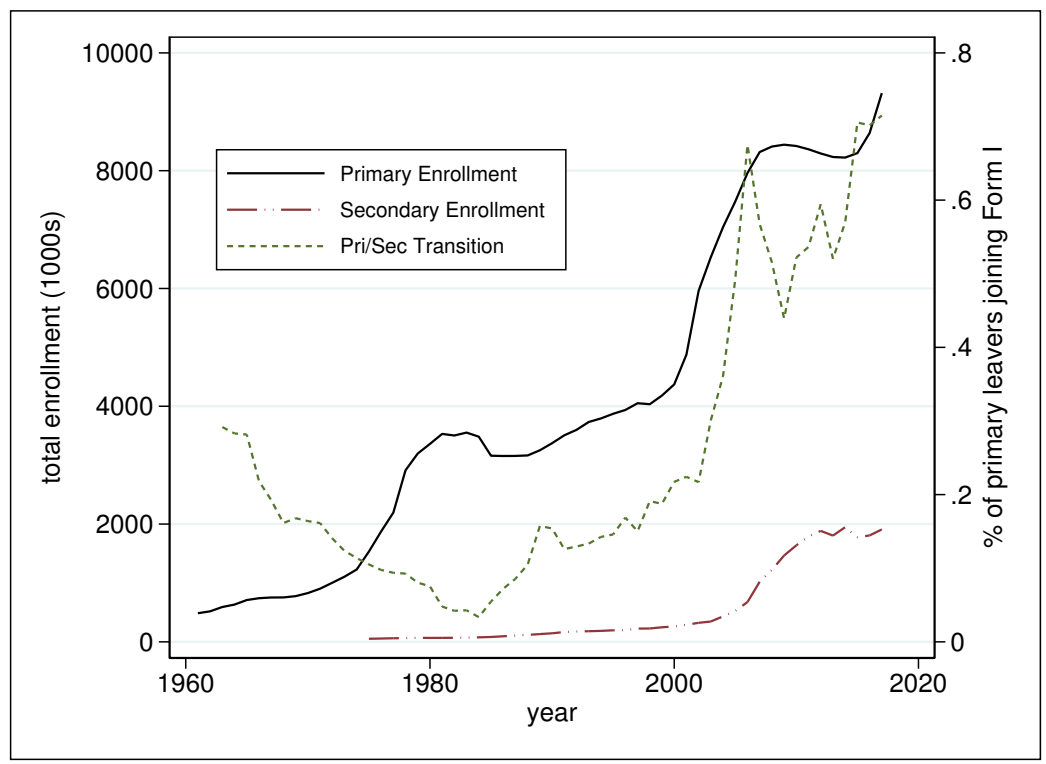

Trend lines indicate gross enrollment rates for primary and secondary schools in African states over time. Notice that secondary enrollment lags primary enrollment. Source: World Bank Indicators Dataset.

of UPE. At the same time, UPE implementation paid little attention to learning outcomes. Providing easily observable and attributable access (school construction and abolition of fees) promised bigger electoral returns. Finally, UPE's success increased demand for secondary education (Figure C.3). By 2011 Africa's secondary schools could absorb only 36 percent of students leaving primary schools. ${ }^{11}$ The unavailability of donor funds for secondary education

\footnotetext{
${ }^{11}$ United Nations. 2011. "2011 Global Education Digest: Coping with the Demand for Sec-ondary Edu-
} 
Figure C.5: Share of Wards Building New Primary Schools and Poverty Rates

\section{Share building new Primary school}
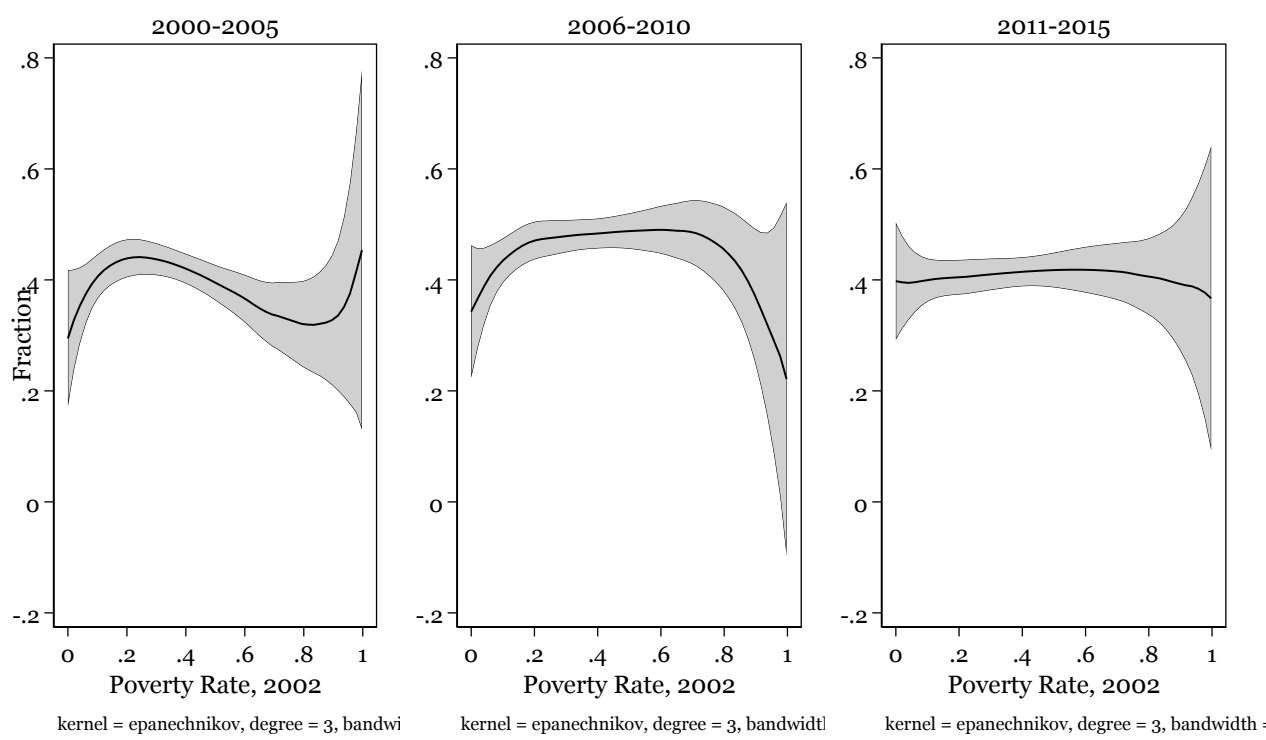

Poverty data are from the 2002 Tanzania National Census. The evidence suggests that primary school construction was widespread across income brackets in Tanzania but, unlike in the case of secondary schools, not particularly more intense between 2006 and 2010.

forced government to raise local revenue as they sought to meet rising demand. ${ }^{12}$ Notice that Tanzania did not engage in any mass school construction in the period under study, as it came well after the end of the UPE era (C.5).

The expansion of access to education in African states illustrates the importance of examining policies' electoral effects throughout the policy cycle, and over multiple electoral periods. UPE's success increased demand for secondary schools. Yet having not anticipated this, African governments lacked the fiscal resources to meet the demand. Some, like Tanzania, foisted the new fiscal burden upon communities and households. ${ }^{13}$ And like in Tanzania, the rapid increases in access (in both primary and secondary education) occasioned declines in learning outcomes. ${ }^{14}$ Many have since reacted with efforts to consolidate access gains, while also trying to improve the quality of learning. Overall, to understand these dynamics requires analyses of policies and associated electoral feedback over time.

cation."

${ }^{12}$ See the case of Ghana: "Ghana Launches Free High School Education," Voice of America, September 15, 2017. Accessed March 17, 2019: https://bit.ly/2y4nr0G; Kenya: "Government to effect full free day secondary learning in January," Daily Nation, November 6, 2017. Accessed March 17, 2019: https://bit. ly/2O8fnVV; and Uganda: "Free universal secondary education in Uganda has yielded mixed results", The Guardian, October 25, 2011. Accessed March 17, 2010: http://tiny.cc/01ag8y

${ }^{13}$ In Uganda, the government resorted to a public private partnership (Barrera-Osorio, De Galbert, Habyarimana and Sabarwal, 2019).

${ }^{14}$ Bold, Filmer, Martin, Molina, Stacy, Rockmore, Svensson and Wane 2017. 